\title{
A Novel Stopped-Flow Assay for Quantitating Carbonic-Anhydrase Activity and Assessing Red-Blood-Cell Hemolysis
}

\author{
Pan Zhao ${ }^{\ddagger}$, R. Ryan Geyer ${ }^{\ddagger \neq}$ and Walter F. Boron * \\ Department of Physiology and Biophysics, Case Western Reserve University School of Medicine, Cleveland, OH, USA
}

\section{OPEN ACCESS}

Edited by:

Francisco Javier Alvarez-Leefmans, Wright State University, USA

Reviewed by:

Pablo Martín-Vasallo, University of La Laguna, Spain

Michael L. Jennings,

University of Arkansas for Medical

Sciences, USA

Mitchell Chesler,

New York University School of

Medicine, USA

${ }^{*}$ Correspondence:

Walter F. Boron

walter.boron@case.edu

${ }^{\dagger}$ Present Address:

R. Ryan Geyer,

Department of Biochemistry, Institute of Chemistry, University of São Paulo,

São Paulo, Brazil

${ }^{\ddagger}$ These authors have contributed equally to this work.

Specialty section:

This article was submitted to Membrane Physiology and Membrane

Biophysics,

a section of the journa

Frontiers in Physiology

Received: 30 December 2016 Accepted: 07 March 2017

Published: 28 March 2017

Citation:

Zhao P, Geyer RR and Boron WF (2017) A Novel Stopped-Flow Assay

for Quantitating Carbonic-Anhydrase Activity and Assessing Red-Blood-Cell

Hemolysis. Front. Physiol. 8:169.

doi: 10.3389/fphys.2017.00169
We report a novel carbonic-anhydrase (CA) assay and its use for quantitating red-blood-cell (RBC) lysis during stopped-flow (SF) experiments. We combine two saline solutions, one containing HEPES/pH 7.03 and the other, $\sim 1 \% \mathrm{CO}_{2} / 44 \mathrm{mM} \mathrm{HCO}_{3}^{-} / \mathrm{pH}$ 8.41, to generate an out-of-equilibrium $\mathrm{CO}_{2} / \mathrm{HCO}_{3}^{-}$solution containing $\sim 0.5 \% \mathrm{CO}_{2} / 22$ $\mathrm{HCO}_{3}^{-} / \mathrm{pH} \sim 7.25\left(10^{\circ} \mathrm{C}\right)$ in the SF reaction cell. CA catalyzes relaxation of extracellular $\mathrm{pH}$ to $7.50: \mathrm{HCO}_{3}^{-}+\mathrm{H}^{+} \rightarrow \mathrm{CO}_{2}+\mathrm{H}_{2} \mathrm{O}$. Proof-of-concept studies (no intact RBCs) show that the $\mathrm{pH}$-relaxation rate constant $\left(\mathrm{k}_{\Delta \mathrm{pH}}\right)$-measured via pyranine fluorescence-rises linearly with increases in [bovine CAIl] or [murine-RBC lysate]. The y-intercept (no CA) was $k_{\Delta \mathrm{pH}}=0.0183 \mathrm{~s}^{-1}$. Combining increasing amounts of murine-RBC lysate with ostensibly intact RBCs (pre-SF hemolysis $\cong 0.4 \%$ )-fixing total [hemoglobin] at $2.5 \mu \mathrm{M}$ in the reaction cell to simulate hemolysis from ostensibly 0 to $100 \%$-causes $k_{\Delta \mathrm{pH}}$ to increase linearly. This $y$-intercept ( $0 \%$ lysate/ $100 \%$ ostensibly intact RBCs) was $k_{\Delta \mathrm{pH}}=0.0820 \mathrm{~s}^{-1}$, and the maximal $k_{\Delta \mathrm{pH}}\left(100 \%\right.$ lysate/0\% intact RBCs) was $1.304 \mathrm{~s}^{-1}$. Thus, mean percent hemolysis in the reaction cell was $\sim 4.9 \%$. Phenol-red absorbance assays yield indistinguishable results. The increase from 0.4 to $4.9 \%$ presumably reflects mechanical RBC disruption during rapid mixing. In all fluorescence studies, the CA blocker acetazolamide reduces $k_{\Delta \mathrm{pH}}$ to near-uncatalyzed values, implying that all CA activity is extracellular. Our lysis assay is simple, sensitive, and precise, and will be valuable for correcting for effects of lysis in physiological SF experiments. The underlying CA assay, applied to blood plasma, tissue-culture media, and organ perfusates could assess lysis in a variety of applications.

Keywords: pH-sensitive dyes, pyranine, phenol red, out-of-equilibrium solutions, acid-based balance, carbon dioxide, bicarbonate

\section{INTRODUCTION}

In the course of using stopped-flow (SF) absorbance spectroscopy to study the effects of inhibitors or the genetic disruption of membrane proteins on the efflux of oxygen $\left(\mathrm{O}_{2}\right)$ from red blood cells (RBCs), we suspected that RBCs were hemolyzing in the SF reaction cell, thereby releasing hemoglobin $(\mathrm{Hb})$ and leading to overestimates of the rate constants for $\mathrm{O}_{2}$ efflux. Moreover, different degrees of hemolysis under different experimental conditions could lead to different extents of overestimation. In our work, the computed percent hemolysis $(\% H)$ of RBC samples entering the SF device is far too low to influence our results appreciably, whereas the $\% H$ of 
material that eventually exits the SF device-this may occur many minutes after a single SF experiment or "shot"-is far too high to be consistent with our $\mathrm{O}_{2}$-efflux data. We therefore set out to develop an assay that could report $\% H$ within the SF reaction cell, and do so in a time domain similar to that of our $\mathrm{O}_{2}$-efflux experiments. Because we are concerned with $\mathrm{Hb}$ in the bulk extracellular fluid (BECF), we devise an assay that: [a] measures a BECF parameter; [b] uses, as far as possible, physiological reactants and products; and targets a substance that $[\mathrm{c}]$ is normally present exclusively in the RBC cytosol (i.e., not normally exposed to the BECF compartment) but [d] would-upon hemolysis-enter the BECF with the same time course as $\mathrm{Hb}$. Two substances that fit this criterion are the highabundance/low-activity enzyme carbonic anhydrase (CA) I and the low-abundance/high-activity CA II (Khalifah, 1971; Dodgson et al., 1988; Sly and Hu, 1995).

Since the discovery of CA by Meldrum and Roughton (1933), investigators have used several approaches for assaying the activity of this enzyme. Virtually simultaneously, Meldrum and Roughton introduced a manometric CA assay (Meldrum and Roughton, 1933), Brinkman introduced a colorimetric variant (Brinkman, 1933), and Stadie and O'Brien introduced an electrometric approach based on a platinum $\mathrm{pH}$ electrode (Stadie and O'Brien, 1933). In 1948, Wilbur and Anderson replaced platinum with a glass $\mathrm{pH}$ electrode (Wilbur and Anderson, 1948). All of these approaches are intrinsically slow and thus require that the preparation be a low temperature $\left(0^{\circ} \mathrm{C}\right)$. After the introduction of stopped-flow devices by Chance in 1950 (Chance, 1950), several investigators used stopped-flow absorbance or fluorescence spectroscopy to study the kinetics of CA (Gibbons and Edsall, 1963, 1964; Ho and Sturtevant, 1963; Kernohan, 1964, 1965; Khalifah, 1971; Wistrand et al., 1975; Pocker and Bjorkquist, 1977; Crandall and O’Brasky, 1978; DeGrado et al., 1982; Sanyal et al., 1982; Baird et al., 1997; Shingles and Moroney, 1997; Wang et al., 2010). These early reports had in common the mixing of two solutions having dissimilar $\mathrm{CO}_{2} / \mathrm{HCO}_{3}^{-} / \mathrm{pH}$ status, and the monitoring of the subsequent time course of at least one parameter from a $\mathrm{pH}$-sensitive dye. Except for one case (Shingles and Moroney, 1997), these earlier papers provided only rudimentary experimental detail, raising the concern that at least one of the two initial solutions had a $\mathrm{pH}$ sufficiently extreme as to be incompatible with living cells. Later investigators introduced CA assays based on continuous-flow calorimetry (Kernohan and Roughton, 1968), the release of ${ }^{14} \mathrm{CO}_{2}$ (Stemler, 1993), and the exchange of ${ }^{18} \mathrm{O}$-labeled $\mathrm{CO}_{2} / \mathrm{HCO}_{3}^{-}$as measured by mass spectrometry (Itada and Forster, 1977). Although the authors' main objective in the ${ }^{18} \mathrm{O}$-exchange study was to measure the $\mathrm{CA}$ activity of intact RBCs, they recognized that their assay is very sensitive to small degrees of CA released by hemolysis.

\footnotetext{
Abbreviations: App \%H, apparent percent hemolysis; App \%Int, apparent percent intact RBCs; $\% H$, percent hemolysis; $\% \mathrm{~L}$, percent lysate; $k_{\Delta \mathrm{pH}}$, the rate constant of $\mathrm{pH}$ relaxation; $k_{\mathrm{RBC}, \text { OstInt }}, k_{\Delta \mathrm{pH}}$ in the presence of ostensibly $100 \%$ intact RBCs; $k_{\mathrm{RBC}, \text { Lysate }}, k_{\triangle \mathrm{pH}}$ in the presence of $100 \%$ lysate; $k_{\text {cat,max }}$, portion of $k_{\mathrm{RBC} \text {,Lysate }}$ due to the maximally catalyzed CA reaction; $k_{\text {cat,min }}$, portion of $k_{\mathrm{RBC} \text {,OstInt }}$ due to the minimally catalyzed CA reaction; $k_{\text {uncat }}$, uncatalyzed rate constant; RxCell, stopped-flow reaction cell.
}

Nevertheless, none of these approaches is easily translated to a SF platform as a method for assessing hemolysis in real time.

Here, we describe novel methods for assaying CA activity in a SF device, and then extending these assays to assess $\mathrm{RBC}$ hemolysis. Our CA assay exploits earlier work from our laboratory to generate out-of-equilibrium (OOE) $\mathrm{CO}_{2} / \mathrm{HCO}_{3}^{-}$ solutions (Zhao et al., 1995) with virtually any combination of $\left[\mathrm{CO}_{2}\right],\left[\mathrm{HCO}_{3}^{-}\right]$, and $\mathrm{pH}$, even somewhat beyond the pathophysiological range of values. In the present study, we combine two dissimilar $\mathrm{CO}_{2} / \mathrm{HCO}_{3}^{-}$solutions-solution (A) $0 \% \mathrm{CO}_{2} / 0 \mathrm{HCO}_{3}^{-} / \mathrm{pH} 7.03$ and solution (B) $1 \% \mathrm{CO}_{2} / 44 \mathrm{mM}$ $\mathrm{HCO}_{3}^{-} / \mathrm{pH} 8.41$ - to create in the reaction cell of an SF device a predetermined initial OOE state-0.5\% $\mathrm{CO}_{2} / 22 \mathrm{mM} \mathrm{HCO}_{3}^{-} / \mathrm{pH}$ $\sim 7.25$-in which the $\mathrm{pH}$ is far too low for the predetermined $\left[\mathrm{CO}_{2}\right] /\left[\mathrm{HCO}_{3}^{-}\right]$ratio. Thus, the system spontaneously undergoes the reactions $\mathrm{HCO}_{3}^{-}+\mathrm{H}^{+} \stackrel{\text { rapid }}{\longrightarrow} \mathrm{H}_{2} \mathrm{CO}_{3} \stackrel{\text { slow }}{\longrightarrow} \mathrm{CO}_{2}+\mathrm{H}_{2} \mathrm{O}$, causing $\mathrm{pH}$ in the $\mathrm{SF}$ reaction cell to rise to $\sim 7.50$. Because $\mathrm{CA}$ catalyzes the reaction $\mathrm{HCO}_{3}^{-}+\mathrm{H}^{+} \stackrel{\mathrm{CA}}{\longrightarrow} \mathrm{CO}_{2}+\mathrm{H}_{2} \mathrm{O}$ (effectively bypassing the slow $\mathrm{H}_{2} \mathrm{CO}_{3}$ dehydration), we can use the time course of $\mathrm{pH}$, reported by the fluorescent dye pyranine (also known as HPTS for 8-hydroxypyrene-1,3,6-trisulfonic acid, trisodium salt) or the non-fluorescent dye phenol red, to compute CA activity. We validate this technique on purified bovine CA II (bCAII) and hemolysates of mouse blood, and then apply it to ostensibly intact murine RBCs, where we find that the actual hemolysis is $\sim 4.9 \%$. Given the sensitivity, precision, and ease of our methodology, this approach could be valuable for assessing CA release (i.e., lysis) from virtually any membranebound structure during SF experiments, or for detecting CA release from fluid that was previously in contact with living cells.

\section{MATERIALS AND METHODS}

\section{Ethical Approval}

Protocols for housing and handling of mice were approved by the Institutional Animal Care and Use Committee at Case Western Reserve University.

\section{Solutions}

The compositions of solutions are shown in Table 1. For the CA assay, we combined solution A with solution B in the SF device to obtain the initial OOE solution ("Mix") in the reaction cell. To achieve the desired $\mathrm{pH}$, we titrated solutions with $\mathrm{NaOH}$ or $\mathrm{HCl}$ either at room temperature (RT, for RBC washing solution) or at $10^{\circ} \mathrm{C}$ (for $\mathrm{pH}$ calibration solution and $\mathrm{OOE} \mathrm{A}$ and $\mathrm{B}$ solutions). $\mathrm{pH}$ measurements were recorded on a portable $\mathrm{pH}$ meter (model A121 Orion Star, Thermo Scientific, Beverly, MA) fitted with a $\mathrm{pH}$ electrode (Ross Sure-Flow combination $\mathrm{pH}$ Electrode, Thermo Scientific) at RT or at $10^{\circ} \mathrm{C}$. For all work at $10^{\circ} \mathrm{C}$-both $\mathrm{pH}$ titration of solutions and the actual experiments-we used a refrigerated, constant-temperature, shaker water bath (model RWB 3220, Thermo Fisher Scientific Inc., Asheville, NC) and several Telesystem magnetic stirrers (Thermo Fisher Scientific). Beakers containing the $\mathrm{pH}$ calibration buffers ( $\mathrm{pH}$ at 6,8, and 10, Fisher Scientific, Fair Lawn, NJ), the solutions to be titrated, and the $\mathrm{pH}$ electrode in its storage solution (Beckman Coulter, Inc. 
TABLE 1 | Physiological solutions.

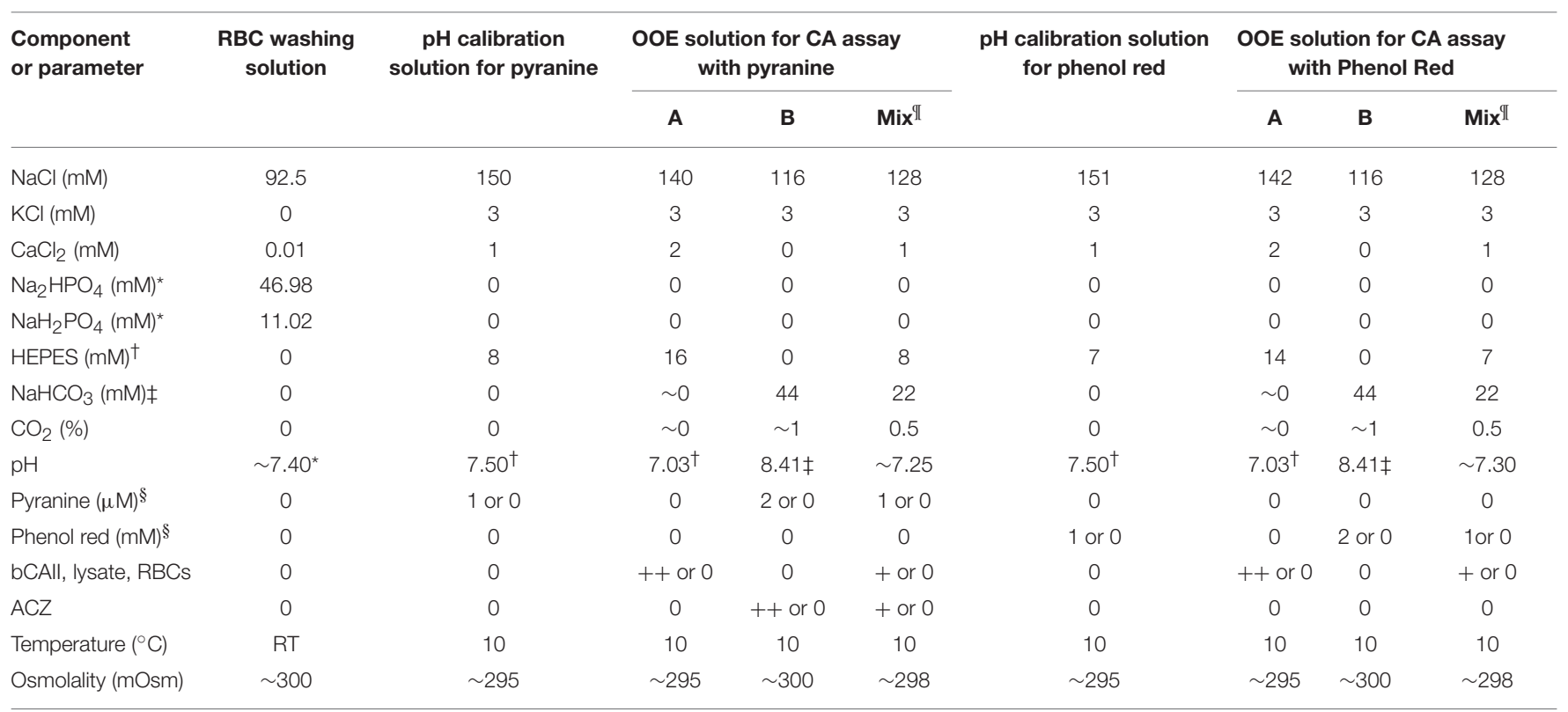

*The ratio $\left[\mathrm{HPO}_{4}^{=}\right] /\left[\mathrm{H}_{2} \mathrm{PO}_{4}^{-}\right]$determines the $\mathrm{pH}$ at $\mathrm{RT}\left(\sim 22^{\circ} \mathrm{C}\right)$.

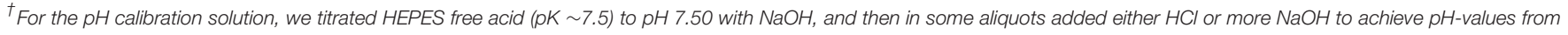

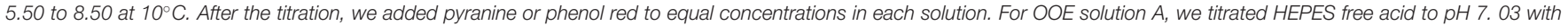
$\mathrm{NaOH}$.

IThe addition of $\mathrm{HCO}_{3}^{-}$generates some $\mathrm{CO}_{2}$ and $\mathrm{CO}_{3}^{=}$; this mixture determined the final $\mathrm{pH}$ at $10^{\circ} \mathrm{C}$.

$\S$ [Pyranine] was present at a concentration of $1 \mu \mathrm{M}$ in the reaction cell (to obtain $\mathrm{pH}$ data) or $0 \mu \mathrm{M}$ (to obtain background data).

$\S$ [Phenol Red] was present at a concentration of $1 \mathrm{mM}$ in the reaction cell (to obtain $\mathrm{pH}$ data) or $0 \mathrm{mM}$ (to obtain background data).

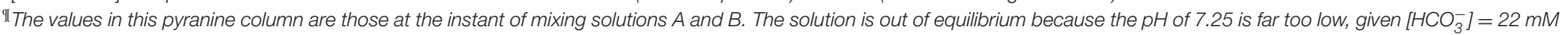
and $\mathrm{CO}_{2}=0.5 \%$.

IThe values in this Phenol Red column are those at the instant of mixing solutions $A$ and $B$.

Brea, CA) were equilibrated, as appropriate, at either RT or $10^{\circ} \mathrm{C}$. Osmolality was measured using a vapor pressure osmometer (Vapro 5520; Wescor, Inc., Logan, UT), and adjusted upward if necessary by the addition of $\mathrm{NaCl}$.

\section{Stopped-Flow Fluorescence Spectroscopy Data Acquisition and Analysis}

We rapidly combined solutions $\mathrm{A}$ and $\mathrm{B}$ using the SX-20 stopped-flow apparatus (Applied Photophysics, Leatherhead, $\mathrm{UK})$. We excited the $\mathrm{pH}$-sensitive fluorescent dye pyranine (H348, Invitrogen, Eugene, OR, USA; see Avnir and Barenholz (2005) using an excitation wavelength of $460 \mathrm{~nm}$ ( $\mathrm{pH}$-sensitive wavelength), or of $415 \mathrm{~nm}$ ( $\mathrm{pH}$-independent isosbestic point), while monitoring total fluorescence emission using a $488 \mathrm{~nm}$ long-pass filter. The sampling period of the SF device was $12.5 \mu \mathrm{s}$. Because the output of the device was 1 data point every $0.1 \mathrm{~s}$, each data point represents $\left(10^{-1} \mathrm{~s}\right) /\left(12.5 \times 10^{-6} \mathrm{~s}\right)=8,000$ samples. Our duration of data collection ranged from 20 s (i.e., 200 data points) for rapid reactions (i.e., high CA activity, A) to $200 \mathrm{~s}$ (i.e., 2000 data points) for slow reactions (e.g., the uncatalyzed reaction, where $A=1$, the minimum value).

For each new experimental sample of solutions A and B (see Table 1), we began by performing six SF shots to ensure that the new solutions were loaded into the reaction cell, and then sequentially acquired four time courses. First, we acquired two time courses in which solution B contained no dye (see Table 1), one a time course of $I_{\text {Background,460 }}$ during one stopped-flow shot while exciting at $460 \mathrm{~nm}$, and then a time course of $I_{\text {Background,415 }}$ during a second shot while exciting at $415 \mathrm{~nm}$. Then we replaced solution $\mathrm{B}$ with one that had an identical composition except for the inclusion of dye (see Table 1), performed six additional SF shots, and then acquired two time additional courses, one while

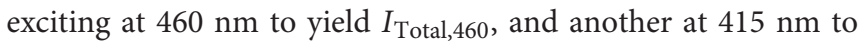
yield $I_{\text {Total,415. }}$. After correcting for background, we obtained for each experimental sample the time course of the ratio $\left(I_{460} / I_{415}\right)$ $=\left[\left(I_{\text {Total }, 460}-I_{\text {Background,460 }}\right) /\left(I_{\text {Total,415 }}-I_{\text {Background }, 415}\right)\right]$, which we converted to the time course of $\mathrm{pH}$ as described below. For some samples, solution B contained acetazolamide (see Table 1). After each experimental sample-for which we acquired four sequential time courses as outlined above-we extensively flushed $(2 \times 2.5 \mathrm{ml}$ in each syringe $)$ both the " $A$ " and " $\mathrm{B}$ " lines of the SF device with OOE "A" buffer (for the " $A$ " line) or " $B$ " buffer (for the " $B$ " line). The exception was that we did not flush line " $A$ " between samples in a sequence of ascending [bCAII] in Figure 2, or ascending RBC lysate in Figure 3.

\section{Calibration of Dye}

We chose pyranine (HPTS) as our fluorescent $\mathrm{pH}$ indicator because others have found it suitable for monitoring extracellular $\mathrm{pH}$; its favorable properties include a low rate of permeation across cell membranes (Shingles and Moroney, 1997; Avnir and 
Barenholz, 2005; Han and Burgess, 2010). We calibrated the $\mathrm{pH}$ indicator dye pyranine at $10^{\circ} \mathrm{C}$ by mixing, in the SF device, two identical solutions that were either the $\mathrm{pH}-7.50$ " $\mathrm{pH}$ calibration solution for pyranine" listed in Table 1, or variants thereof obtained by titrating the $\mathrm{pH}$ as outlined in a footnote to Table 1 . For each $\mathrm{pH}$-value $\mathrm{X}$, we computed $\left(I_{460} / I_{415}\right)_{\mathrm{pHx}}$ as described in the previous section. Using an approach described previously for another $\mathrm{pH}$-sensitive fluorophore (Boyarsky et al., 1988), we fitted the following theoretical titration curve to our experimental data:

$$
\frac{\left(I_{460} / I_{415}\right)_{\mathrm{pHx}}}{\left(I_{460} / I_{415}\right)_{\mathrm{pH} 7.5}}=1+b\left[\frac{10^{(\mathrm{pHx}-\mathrm{pK})}}{1+10^{(\mathrm{pHx}-\mathrm{pK})}}-\frac{10^{(7.5-\mathrm{pK})}}{1+10^{(7.5-\mathrm{pK})}}\right]
$$

which normalizes the data to the value observed at $\mathrm{pH} 7.5$, and forces the function to have a value of unity at this $\mathrm{pH}$. Here, $b$ is the difference between the maximal and minimal asymptotic values of $\left(I_{460} / I_{415}\right)_{\mathrm{pHx}} /\left(I_{460} / I_{415}\right)_{7.5}$.

We used an iterative, non-linear least-squares method (Boyarsky et al., 1988) to determine $b$ and pK. Figure 1A shows a plot of the data from five sets of experiments, as well as the bestfit curve. The best-fit values were $7.11 \pm 0.01(S D)$ for the $\mathrm{pK}$, and $1.39 \pm 0.01(S D)$ for $b$. We used these values of $\mathrm{pK}$ and $b-$ obtained at $10^{\circ} \mathrm{C}$-and the values for ratio of $\left(I_{460} / I_{415}\right)$ in each experiment to calculate $\mathrm{pH}$. Others have reported $\mathrm{pK}$-values for pyranine of 7.24 at RT (Avnir and Barenholz, 2005) and $~ 7.3$ at $25^{\circ} \mathrm{C}$ (Han and Burgess, 2010).

\section{Stopped-Flow Absorbance Spectroscopy Data Acquisition and Analysis}

Using an approach similar to that outlined above for stoppedflow fluorescence spectroscopy, we used stopped-flow absorbance spectroscopy with the non-fluorescent $\mathrm{pH}$-sensitive dye phenol red (P4633, Sigma-Aldrich, St. Louis, MO) to record absorbance at wavelengths of $570 \mathrm{~nm}$ ( $\mathrm{pH}$-sensitive wavelength) and $480 \mathrm{~nm}$ ( $\mathrm{pH}$ isosbestic wavelength; Hollingworth and Baylor, 1990). The sampling period was $12.5 \mu \mathrm{s}$, and the duration of data collection ranged from 20 to $200 \mathrm{~s}$.

For each experimental sample, we acquired two time courses in the absence of dye (Table 1), $A_{\text {Background,570 and }}$

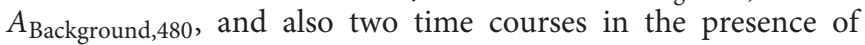
dye (Table 1), $A_{\text {Total,570 }}$ and $A_{\text {Total,480. For each experimental }}$ sample, we obtained the time course of the ratio $\left(A_{570} / A_{480}\right)$ $=\left[\left(A_{\text {Total,570 }}-A_{\text {Background,570 }}\right) /\left(A_{\text {Total,480 }}-A_{\text {Background, } 480}\right)\right]$, which we converted to the time course of $\mathrm{pH}$ as described below.

\section{Calibration of Dye}

We chose phenol red as our non-fluorescent $\mathrm{pH}$ indicator because others have found it suitable for long-term monitoring of $\mathrm{pH}$ in cell- or tissue-culture media. We calibrated the $\mathrm{pH}$ indicator phenol red at $10^{\circ} \mathrm{C}$ by mixing, in the SF device, two identical solutions that were either the $\mathrm{pH}-7.50$ " $\mathrm{pH}$ calibration solution for Phenol red" listed in Table 1, or variants thereof at different $\mathrm{pH}$-values (see footnote to Table 1). For each $\mathrm{pH}$-value $\mathrm{X}$, we computed $\left(A_{570} / A_{480}\right)_{\mathrm{pHx}}$, using an equation similar to that described above for pyranine:

$$
\frac{\left(A_{570} / A_{480}\right)_{\mathrm{pHx}}}{\left(A_{570} / A_{480}\right)_{\mathrm{pH} 7.5}}=1+b\left[\frac{10^{(\mathrm{pHx}-\mathrm{pK})}}{1+10^{(\mathrm{pHx}-\mathrm{pK})}}-\frac{10^{(7.5-\mathrm{pK})}}{1+10^{(7.5-\mathrm{pK})}}\right] .
$$

Figure 1B shows a plot of the data from five sets of experiments, as well as the best-fit curve. The best-fit values, obtained using an iterative, non-linear least-squares method (Boyarsky et al., 1988), were $7.61 \pm 0.01(S D)$ for the $\mathrm{pK}$, and $2.45 \pm 0.03(S D)$ for $b$. We used these values of $\mathrm{pK}$ and $b$-obtained at $10^{\circ} \mathrm{C}$-and the values for ratio of $\left(A_{570} / A_{480}\right)$ in each experiment to calculate $\mathrm{pH}$. Others have reported the $\mathrm{pK}$ of phenol red to be 7.67 at $25^{\circ} \mathrm{C}$ (Sendroy and Rodkey, 1961), and 7.73 at $16-17^{\circ} \mathrm{C}$ (Hollingworth and Baylor, 1990).

\section{Carbonic Anhydrase Assay}

For some experiments, we obtained purified bCAII, isolated from erythrocytes (C2522, Sigma-Aldrich, St. Louis, MO), and resuspended it in $0.2 \%$ bovine serum albumin at a concentration of $1 \mathrm{mg} / \mathrm{mL}$. We added varying amounts of bCAII to establish concentrations from 0.5 to $8 \mu \mathrm{g} / \mathrm{mL}$ in solution A (Table 1). Rapid mixing with solution $\mathrm{B}$ (containing $2 \mu \mathrm{M}$ pyranine) at $10^{\circ} \mathrm{C}$ in the SF reaction cell initiates the reactions $\mathrm{HCO}_{3}^{-}+$ $\mathrm{H}^{+} \rightarrow \mathrm{H}_{2} \mathrm{CO}_{3} \rightarrow \mathrm{CO}_{2}+\mathrm{H}_{2} \mathrm{O}$ and $\mathrm{HCO}_{3}^{-}+\mathrm{H}^{+} \stackrel{\mathrm{CA}}{\rightarrow} \mathrm{CO}_{2}$ $+\mathrm{H}_{2} \mathrm{O}$, causing $\mathrm{pH}$ to rise exponentially. Under stopped-flow conditions, we exploited the fluorescence of pyranine to monitor this $\mathrm{pH}$ trajectory as described above. In other experiments, instead of adding bCAII to solution A, we added murine RBC lysate (described below), murine RBCs (described below), or mixtures of the two. In some of the lysate and RBC experiments, we instead exploited the absorbance of phenol red.

Regardless of the dye used, we fitted the $\mathrm{pH}$ time course with the equation

$$
\mathrm{pH}(t)=A-B e^{-\left(k_{\Delta p H}\right) t}
$$

where $t$ is time, $A$ is the final (equilibrated) value of $\mathrm{pH}, B$ is the $\mathrm{pH}$ range, and $k_{\Delta \mathrm{pH}}$ is the rate constant of the $\mathrm{pH}$ relaxation. We obtained $A, B$, and $k_{\Delta \mathrm{pH}}$ using a non-linear least-squares method.

\section{Blood Collection}

Prior to blood collection, a 1-mL syringe and attached 23-gauge needle were rinsed with $0.1 \%$ sodium heparin (H4784, SigmaAldrich). Adult C57/BL6 wild type (WT) mice (8-16 weeks old) were sacrificed by cervical dislocation and blood was immediately collected by the cardiac-puncture method (Parasuraman et al., 2010) using the aforementioned syringe and needle. The blood was transferred to a $1.5-\mathrm{mL}$ tube, centrifuged in a Beckman Microfuge 16 Microcentrifuge (Beckman, Brea, CA) at 600 $\times \mathrm{g}$ for $10 \mathrm{~min}$ and the resulting supernatant $\# 0$ and buffy coat were removed. To remove residual extracellular $\mathrm{Hb}$, the pelleted RBCs were resuspended ("resuspended RBCs") in RBC washing solution (Table 1) to a $\sim 5-10 \%$ hematocrit (Hct), and centrifuged at $600 \times \mathrm{g}$ for $5 \mathrm{~min}$. The supernatant from this centrifugation is supernatant \#1. This process was repeated $3 \times$, with an estimation of percent hemolysis (see below) performed at each step. After these four washes, RBCs were resuspended in 

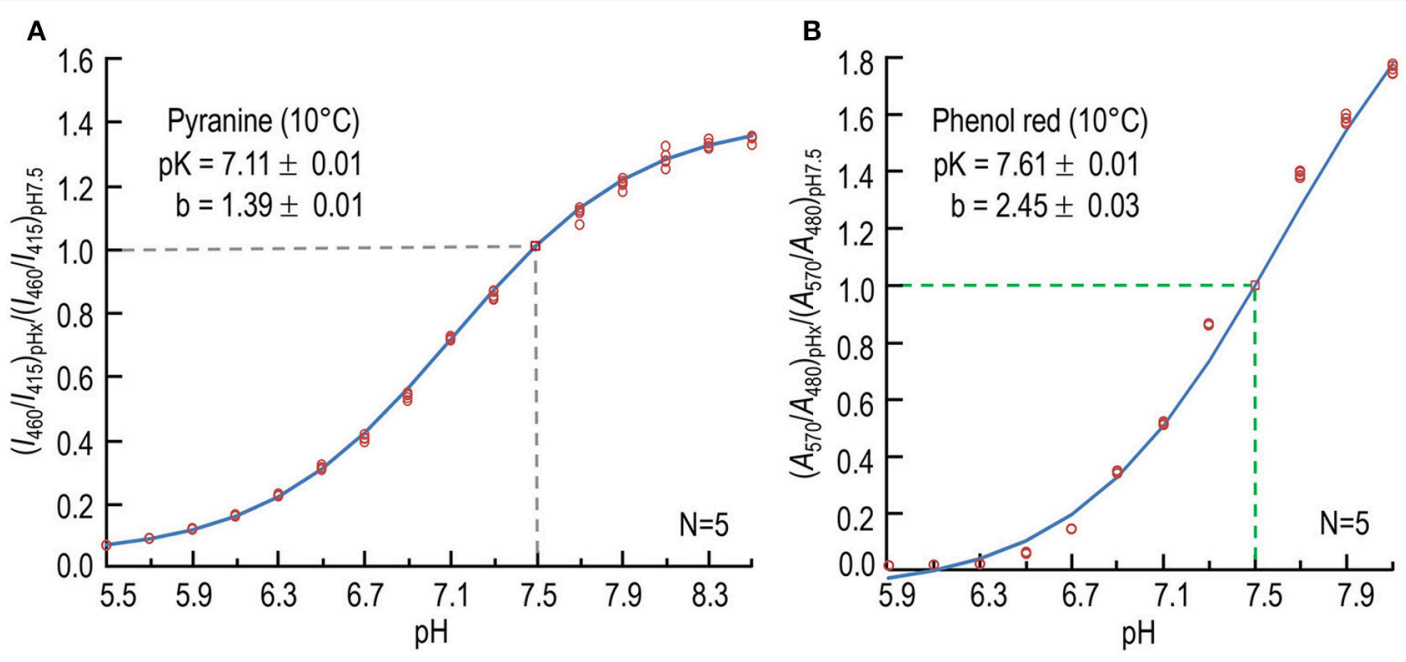

FIGURE 1 | Calibration of pH-sensitive dyes at $\mathbf{1 0}^{\circ} \mathbf{C}$. (A) Dependence of normalized fluorescence-excitation ratio of pyranine on pH. For each data point at one of $16 \mathrm{pH}$-values $\left(\mathrm{pH}_{\mathrm{x}}\right.$ ), we record the time course of fluorescence emission ( $\geq 488 \mathrm{~nm}$ ) in the stopped-flow device separately at excitation wavelengths of 460 and 415 $\mathrm{nm}$, first in the absence and then in the presence of dye, and obtain the background-subtracted ratio $\left(\mathrm{I}_{460} / \mathrm{I}_{415}\right)_{\mathrm{pHx}}$, as described in Section Materials and Methods. We then divide each $\left(\mathrm{I}_{460} / \mathrm{I}_{415}\right)_{\mathrm{pHx}}$ by the value observed at $\mathrm{pH} 7.50$ in that experiment to obtain the normalized fluorescence-excitation ratio

$\left(\mathrm{I}_{460} / \mathrm{I}_{415}\right)_{\mathrm{pHx}} /\left(\mathrm{I}_{460} / \mathrm{I}_{415}\right)_{\mathrm{pH}}$ 7.5. The value 7.11 is the best-fit value for $\mathrm{pK}$, and 1.39 is the best-fit value for the difference between the maximal and minimal asymptotic values of $\left(I_{460} / I_{415}\right)_{\mathrm{pH}_{\mathrm{x}}} /\left(\mathrm{I}_{460} / /_{415}\right)_{7.5}$. The data are from five sets of experiments. (B) Dependence of normalized absorbance ratio of phenol red on pH. For each data point at one of $12 \mathrm{pH}$-values $\left(\mathrm{pH}_{\mathrm{X}}\right)$, we record absorbance separately at the $\mathrm{pH}$-sensitive wavelength of $570 \mathrm{~nm}$ and at the isosbestic wavelength of $480 \mathrm{~nm}$. After subtracting the background at each incident wavelength, we obtain the ratio $\left(\mathrm{A}_{570} / \mathrm{A}_{480}\right)_{\mathrm{pHx}}$. We then normalize each $\left(\mathrm{A}_{570} / \mathrm{A}_{480}\right)_{\mathrm{pHx}}$ to the value observed at pH 7.50 in that experiment, as described in Section Materials and Methods. The data are from five sets of experiments. In both (A,B), we show each individual point, some of which overlie other. $N$ is the number of experiments in each experiment, we obtained data for each $\mathrm{pH}$. The curves through the points - and the $\mathrm{pK}$ and $b$-values $( \pm S D)$-are the result of non-linear least-squares calculations.

RBC washing solution to a final Hct of $25-30 \%$, and maintained for up to $\sim 5 \mathrm{~h}$ on ice for experiments performed that day.

We computed the $\mathrm{Hb}$ concentration, $[\mathrm{Hb}]$, using a novel least-square's approach, based on Beer's law. It is well-known that pure $\mathrm{Hb}$ has an absorbance at $650 \mathrm{~nm}\left(A_{650}\right)$ of $\sim 0$ (Philo et al., 1981; Barlow et al., 1992; Hernández et al., 2009), and we found that $A_{650}$ is likewise $\sim 0$ in RBC hemolysates (data not shown; preparation described in next section). When we compared absorbance spectra of ostensibly intact RBCs with those of RBC lysates of equal [Hb] value, we found that they were virtually identical except that the spectra for ostensibly intact RBCs were displaced upward by almost exactly $A_{650}$ (not shown). Therefore, to compute $[\mathrm{Hb}]$-regardless of whether we were dealing with samples of ostensibly intact RBCs or RBC lysate-we determined $A_{560}, A_{576}$, and $A_{650}$ on a Beckman Coulter 730 Life Science UV/Vis Spectrophotometer (Beckman, Brea, CA), using the following equation (see following section for derivation):

$$
[\mathrm{Hb}](\mathrm{M})=\frac{\left(A_{560}-A_{650}\right)^{2}+\left(A_{576}-A_{650}\right)^{2}}{\ell \varepsilon_{560}\left(A_{560}-A_{650}\right)+\ell \varepsilon_{576}\left(A_{576}-A_{650}\right)},
$$

where $l$ is the pathlength of $1 \mathrm{~cm}$, the molar extinction coefficient for oxy-hemoglobin at $560 \mathrm{~nm}\left(\varepsilon_{560}\right)$ is $32,613.2 \mathrm{~cm}^{-1} \mathrm{M}^{-1}$, and $\varepsilon_{576}$ is $55,540 \mathrm{~cm}^{-1} \mathrm{M}^{-1}$ (Prahl, 1998).

After the initial centrifugation of whole blood, we estimated percent hemolysis after determining $[\mathrm{Hb}]$ in (a) the blood plasma (i.e., supernatant \#0; see definition, above), and (b) in the pelleted
RBCs after their resuspension in RBC washing solution, using the equation:

$\% H$ before first wash

$$
=\frac{[\mathrm{Hb}]_{\text {Supernatant \# } 0} \times V_{\text {Supernatant\#0 }}}{\left([\mathrm{Hb}]_{\text {Supernatant \#0 }} \times V_{\text {Supernatant \#0 }}\right)+},
$$

where $V$ is volume. In Figure $\mathbf{5 A}$, the resulting value is plotted as "Number of washes of RBCs" $=0$.

After each step $i$ of RBC washing, we estimated $\% H$ hemolysis by determining $[\mathrm{Hb}]$ in the supernatant $\# i$ and the resuspended RBCs:

$$
\begin{aligned}
& \% H \text { after wash } \# i \\
& =\frac{[\mathrm{Hb}]_{\text {Supernatant } \# i} \times V_{\text {Supernatant } \# i}}{\left([\mathrm{Hb}]_{\text {Supernatant } \# 0} \times V_{\text {Supernatant } \# 0}\right)+}, \\
& \left([\mathrm{Hb}]_{\text {Resuspended RBCs }} \times V_{\text {Resuspended RBCs }}\right)
\end{aligned}
$$

where $V$ is volume. In Figure 5A, the resulting values are plotted as "Number of washes of RBCs" $=1,2,3$, and 4 . Because a tiny fraction of RBCs may hemolyzed with each wash, the preceding equation may slightly underestimate the true $\% H$.

\section{Derivation of Equation for Hemoglobin Concentration}

According to the Beer-Lambert law, the hemoglobin concentration is $[\mathrm{Hb}]=A_{\lambda} / \ell \varepsilon_{\lambda}$, where $A_{\lambda}$ is absorbance at 
wavelength $\lambda, \ell$ is pathlength $(\mathrm{cm})$, and $\varepsilon_{\lambda}$ is the molar extinction coefficient $\left(\mathrm{cm}^{-1} \mathrm{M}^{-1}\right)$.

To determine the concentration $(C)$ from the following equation:

$$
[\mathrm{Hb}](\mathrm{M})=C=\frac{A}{\ell \varepsilon}
$$

we used a least-squares method. To avoid inaccuracies caused by dividing by $\varepsilon$, which varies substantially, consider

$$
\frac{A}{C}-\ell \varepsilon=0 \text {. }
$$

If we denote

$$
\bar{C}=\frac{1}{C}
$$

then

$$
A \bar{C}-\ell \varepsilon=0 .
$$

In the present study, we obtain three absorbance values- $A_{560}$ ( $560 \mathrm{~nm}$ is a local valley for oxygenated $\mathrm{Hb}), A_{576}(576 \mathrm{~nm}$ is a local peak), and $A_{650}\left(650 \mathrm{~nm}\right.$ is $\mathrm{O}_{2}$ independent) - from which we derive $A_{1}=A_{560}-A_{650}$ and $A_{2}=A_{576}-A_{650}$. Because each derived $A$-value has a corresponding $\varepsilon$-value, we have two data points $\left(A_{1}, \varepsilon_{1}\right)$ and $\left(A_{2}, \varepsilon_{2}\right)$. The objective of the least-squares method is to find the best-fit value of $C$ that minimizes the value of the following function:

$$
F=\left(A_{1} \bar{C}-\ell \varepsilon_{1}\right)^{2}+\left(A_{2} \bar{C}-\ell \varepsilon_{2}\right)^{2} .
$$

This minimum occurs when

$$
\frac{d F}{d \bar{C}}=0,
$$

which occurs when

$$
\begin{gathered}
2 A_{1}\left(A_{1} \bar{C}-\ell \varepsilon_{1}\right)+2 A_{2}\left(A_{2} \bar{C}-\ell \varepsilon_{2}\right)=0, \\
\bar{C}\left(A_{1}^{2}+A_{2}^{2}\right)-\ell\left(A_{1} \varepsilon_{1}+A_{2} \varepsilon_{2}\right)=0, \\
\bar{C}=\frac{\ell\left(A_{1} \varepsilon_{1}+A_{2} \varepsilon_{2}\right)}{A_{1}^{2}+A_{2}^{2}} .
\end{gathered}
$$

Thus, the concentration $(C)$ is:

$$
C=\frac{A_{1}^{2}+A_{2}^{2}}{\ell\left(A_{1} \varepsilon_{1}+A_{2} \varepsilon_{2}\right)} .
$$

\section{Simulated Hemolysis}

An RBC lysate was produced by osmotic lysis of $20 \mu \mathrm{L}$ of freshly prepared, packed mouse RBCs (see above) in Milli-Q $\mathrm{H}_{2} \mathrm{O}$ (Milli-Q ${ }^{\circledR}$ Integral Water Purification System, EMD Millipore Corporation, Billerica, MA) of $\sim 1: 8$ dilution, followed by centrifugation at $15000 \times \mathrm{g}$ for $5 \mathrm{~min}$ in a Beckman Microfuge 16 at RT. The supernatant (cleared of cellular debris) then was removed and the hemolysate was transferred to a clean $1.5 \mathrm{~mL}$ tube for a spectroscopic determination of $[\mathrm{Hb}]$ as described above.

We achieved simulated degrees of hemolysis (Table 2, column 1 ), ranging from $0 \%$ (an apparent value) to $100 \%$ (an actual value) by combining different proportions of (a) freshly prepared, ostensibly intact RBCs (Table 2, column 2) and (b) a lysate (representing 100\% lysis; Table 2, column 3), while maintaining the total $[\mathrm{Hb}]$ at $2.5 \mu \mathrm{M}$ in the $\mathrm{SF}$ reaction cell.

\section{Analysis of Data}

We report results as mean $\pm S D$. We analyze data using twotailed unpaired student's $t$-test or two-tailed paired student's $t$ test, considering $P<0.05$ as significant. In Figure 5A, we also applied the Holm-Bonferroni correction for the 10 comparisons and using $\alpha=0.05$ (Holm, 1979).

\section{RESULTS}

We developed a novel CA assay, based on the first use of outof-equilibrium $\mathrm{CO}_{2} / \mathrm{HCO}_{3}^{-}$solutions in a stopped-flow device. OOE technology makes it possible to generate, for a brief period of time, solutions in which $\mathrm{CO}_{2}, \mathrm{HCO}_{3}^{-}$and $\mathrm{H}^{+}$are predictably out of equilibrium, even though each of their concentrations may have near-physiological values (Zhao et al., 1995). We use the fluorescent dye pyranine and SF fluorescence spectroscopy for most of our analyses. However, in some experiments, we use the dye phenol red and SF absorbance spectroscopy. We choose an SF temperature of $10^{\circ} \mathrm{C}$ to match the condition of our parallel $\mathrm{O}_{2}$ study, and at the same time maintain a suitable CA catalytic rate. We choose the $\mathrm{pH}$ to be $\sim 7.25$ at the instant of mixing in the SF reaction cell. Over the ensuing seconds, the net reaction $\mathrm{HCO}_{3}^{-}+\mathrm{H}^{+} \rightarrow \mathrm{CO}_{2}+\mathrm{H}_{2} \mathrm{O}$ causes $\mathrm{pH}$ to rise exponentially to $\sim 7.50$. We estimate ${ }^{1}$ that, during this time, $\left[\mathrm{HCO}_{3}^{-}\right]$falls from 22.0 to $21.16 \mathrm{mM}$, and that $\left[\mathrm{CO}_{2}\right]$ rises by the same amount, from $0.23 \mathrm{mM}$ (i.e., $0.5 \% \mathrm{CO}_{2}$ ) to $1.06 \mathrm{mM}$. Because the Hct in the SF reaction cell is $\sim 0.15 \%$ (see below), any traffic of $\mathrm{CO}_{2}$ or $\mathrm{HCO}_{3}^{-}$across the $\mathrm{RBC}$ membrane would have only trivial effects on extracellular composition. We assume that changes in intracellular composition would not affect the degree of hemolysis.

\section{TABLE 2 | Establishing the fraction of apparent hemolysis.}

\begin{tabular}{lcc}
\hline$\%$ Apparent hemolysis (\%) & Intact RBCs* (\%) & RBC hemolysate* (\%) \\
\hline 0 & 100 & 0 \\
5 & 95 & 5 \\
10 & 90 & 10 \\
25 & 75 & 25 \\
50 & 50 & 50 \\
100 & 0 & 100 \\
\hline
\end{tabular}

${ }^{*} 100 \%$ refers to $2.5 \mu \mathrm{M}$ hemoglobin in the reaction cell.

${ }^{1} \mathrm{We}$ assumed that the system is closed for $\mathrm{CO}_{2} / \mathrm{HCO}_{3}^{-}$, with initial $\left[\mathrm{CO}_{2}\right]=0.23$ $\mathrm{mM}$, initial $\left[\mathrm{HCO}_{3}^{-}\right]=22 \mathrm{mM}, \mathrm{pK}=6.2$, and final $\mathrm{pH}=7.50$. The difference between the decrement in $\left[\mathrm{HCO}_{3}^{-}\right]$and the increment in $\left[\mathrm{CO}_{2}\right]$ is due to rounding errors. 


\section{CA Assay on Purified Bovine CA II}

First, we test our CA assay on purified bCAII, over a range of [bCAII] values. The pyranine dye is in the syringe opposite to the one containing bCAII (Table 1). With no added CA $(0 \mu \mathrm{g} / \mathrm{ml})$, $\mathrm{pH}$ rises very slowly, reaching $\sim 7.50$ in $\sim 200 \mathrm{~s}$ (Figure 2A, lowest curve). As we increase the bCAII concentration in the SF reaction cell (i.e., $[\mathrm{bCAII}]_{\mathrm{RxCell}}=0.25,0.5,1,2$, and $4 \mu \mathrm{g} / \mathrm{ml}$ ), the equilibration speeds greatly. Figure $\mathbf{2 B}$ shows the same data as in Figure 2A, but over the first 5 s. For each [bCAII] in Figures 2A,B - and many other similar experiments-we calculate the rate constant of the $\mathrm{pH}$ relaxation, using a leastsquares approach to fit an exponential curve to each set of $(\mathrm{pH}$, t) coordinates that describes the exponential increase in $\mathrm{pH}$ over time. Figure $2 \mathrm{C}$ summarizes the dependence of the rate constant $k_{\Delta \mathrm{pH}}$ on [bCAII] at $10^{\circ} \mathrm{C}$, and shows that graded increases in [bCAII] cause $k_{\Delta \mathrm{pH}}$ to rise linearly. The y-intercept of the line of best fit, $0.0185 \mathrm{~s}^{-1}$, is the rate constant of the uncatalyzed chemical reactions that occur during the $\mathrm{pH}$ relaxation. The slope of the line, $0.8143\left(\mathrm{~s}^{-1}\right) /(\mu \mathrm{g} / \mathrm{ml})$, is a measure of the specific activity of the bCAII.

Next, we studied the effect of CA blocker acetazolamide (ACZ) on bCAII enzymatic activity, adding ACZ to the syringe opposite to the one containing bCAII (Table 1) to achieve a $[\mathrm{ACZ}]_{\mathrm{RxCell}}$ in the reaction cell of $10 \mu \mathrm{M}$. Figures 2D,E, as expected, show that ACZ virtually collapses all the $\mathrm{pH}$ relaxations for the bCAII experiments $(0.25-4 \mu \mathrm{g} / \mathrm{ml})$ onto the curve describing no added bCAII. The summary in Figure $2 \mathrm{~F}$ shows that, over the entire range of [bCAII] values, ACZ reduces $k_{\Delta \mathrm{pH}}$ to nearly the uncatalyzed value.

\section{CA Assay on Mouse RBC Hemolysate}

Second, we extend our work to murine RBC lysates to determine if our CA assay can quantitate hemolysis. The pyranine dye is in the syringe opposite to the one containing $\mathrm{RBC}$ lysate (Table 1). Figures $\mathbf{3 A}, \mathbf{B}$ shows six $\mathrm{pH}$ trajectories, similar to those in Figures 2A,B except that here (Figures 3A,B) we replace bCAII with lysate from WT mouse RBCs. A percent lysate (\%L) of $100 \%$ refers to hemolysate containing $2.5 \mu \mathrm{M} \mathrm{Hb}$ (i.e., Hct $\cong 0.15 \%$ ) in the SF reaction cell; a $\% \mathrm{~L}$ of $50 \%$ refers to half this concentration of hemolysate (diluted in saline), and so on. In the absence of $\mathrm{RBC}$ lysate (i.e., $\% \mathrm{~L}=0 \%$ in Figures $\mathbf{3 A}, \mathbf{B}$ ), $\mathrm{pH}$ rises from $\sim 7.25$ to reach $\sim 7.50$ at a low rate that is similar to what we saw above in Figures 2A,B. Here in Figures 3A,B, we see that increasing \% greatly speeds the equilibration of $\mathrm{pH}$. Figure $3 \mathrm{C}$ summarizes the best-fit $k_{\Delta \mathrm{pH}}$ data from a total of nine mice. As expected, $k_{\triangle \mathrm{pH}}$ has a linear dependence on $\% \mathrm{~L}$, and the $\mathrm{y}$ intercept of $\sim 0.0183 \mathrm{~s}^{-1}$ is nearly identical to the corresponding value in Figure 2C.

Figure $3 \mathrm{D}$ through $F$ show that $\mathrm{ACZ}$, at a $[\mathrm{ACZ}]_{\mathrm{RxCell}}$ of $5 \mu \mathrm{M}$, almost completely eliminates the CA activity of the hemolysate.

\section{CA Assay on Mixtures of Intact and Hemolyzed Mouse RBCs}

In a third set of experiments, we test our CA assay by creating a solution A (Table 1) in which we combine, in different proportions: (a) freshly prepared, ostensibly "intact" RBCs (5 $\mu \mathrm{M} \mathrm{Hb}$, or $\sim 0.3 \% \mathrm{Hct}$ ) with (b) a lysate from an equivalent mass of RBCs ( $5 \mu \mathrm{M} \mathrm{Hb})$. Thus, in the SF reaction cell, after mixing with solution $\mathrm{B}$, all solution $\mathrm{A}$ combinations generate a $\mathrm{Hb}$ concentration $\left([\mathrm{Hb}]_{\mathrm{RxCell}}\right)$-representing the sum of $\mathrm{Hb}$ both inside and outside the RBCs-of $2.5 \mu \mathrm{M}$. Thus, this approach simulates ostensible degrees of hemolysis between 0 and $100 \%$, inclusive. Note that the total CA activity in the reaction cellrepresenting the sum of CAs both inside and outside the RBCs - is also constant across all RBC/lysate mixtures. The pyranine dye is in syringe $B$, opposite to the one containing the $\mathrm{RBC}$ /lysate mixture (Table $\mathbf{1}$ ). Figures $\mathbf{4 A}, \mathbf{B}$ show six $\mathrm{pH}$ trajectories obtained on blood from one mouse, and indicate that the greater the ratio of simulated $\mathrm{RBC}$ hemolysis the faster the equilibration of extracellular $\mathrm{pH}\left(\mathrm{pH}_{\mathrm{o}}\right)$.

Note that an ostensibly $0 \%$ hemolysis (lowest $\mathrm{pH}$ records in Figures 4A,B) produces an equilibration that is considerably faster than the truly uncatalyzed $\mathrm{pH}$ trajectories (i.e., the lowest pH records) in Figures 2A,B, 3A,B. Thus, ostensibly 100\% intact RBCs must, in fact, be partially hemolyzed in the SF reaction cell. Figure 4C summarizes the best-fit $k_{\Delta \mathrm{pH}}$ data from a total of nine mice-the same nine mice as in Figure $3 \mathrm{C}$. The $k_{\Delta \mathrm{pH}}$ vs. percent hemolysis relationship is linear, as in Figures 2C, 3C. However, in Figure $4 \mathrm{C}$, the $\mathrm{y}$-intercept-the $k_{\Delta \mathrm{pH}}$ of ostensibly $100 \%$ intact RBCs from WT mice-is $\sim 0.0820 \mathrm{~s}^{-1}$. This value is more than 4-fold higher than the corresponding $k_{\Delta \mathrm{pH}}$ in Figures $2 \mathrm{C}, 3 \mathrm{C}$, confirming the partial lysis of these cells in the SF reaction cell.

Figures 4D,E show that ACZ, added to the syringe opposite to the one containing the RBC/lysate to achieve a $[\mathrm{ACZ}]_{\mathrm{RxCell}}$ of $5 \mu \mathrm{M}$, almost completely eliminates the CA activity of the mixtures, across the entire range of simulated ostensible hemolysis. Figure $4 \mathrm{~F}$ shows that, for all mixtures, ACZ reduces $k_{\Delta \mathrm{pH}}$ to nearly the uncatalyzed value. The $\mathrm{y}$-intercept in Figure 4F, which represents the near-fully uncatalyzed state, is only $\sim 21 \%$ of the value observed in Figure 4C. Because the pyranine dye and the ACZ first make contact with the RBC/lysate in the SF reaction cell, the dye presumably reports-and the ACZ presumably slows-only the $\mathrm{pH}$ equilibration in the extracellular space, and not inside intact RBCs. Thus, the y-intercept in Figure 4C (which represents $k_{\triangle \mathrm{pH}}$ for the uncatalyzed reaction + CA from lysed RBCs) and the y-intercept in Figure 3C (which represents $k_{\Delta \mathrm{pH}}$ for the uncatalyzed reaction only) provide the information needed to compute hemolysis in the SF cell.

\section{Assessing RBC Hemolysis before and during SF Experiments}

In a fourth set of experiments, we collect fresh whole blood from nice mice-the same nice mice as in Figures 3C, 4C-and obtain an initial hemolysis of $2.36 \pm 1.04 \%$ before any washing (Figure 5A, number of washes $=0$ ). We then wash the RBCs four times in RBC washing solution (Table 1), obtaining the percent hemolysis after each step. After the fourth wash, we arrive at a hemolysis of $0.37 \% \pm 0.21 \%$ (which is significantly $>0 ; P=$ 0.00013 ) before putting the RBCs into the SF device (Figure 5A). Our $\% H$-value of $0.37 \%$, which may slightly underestimate the true value as noted in Section Materials and Methods, is similar 

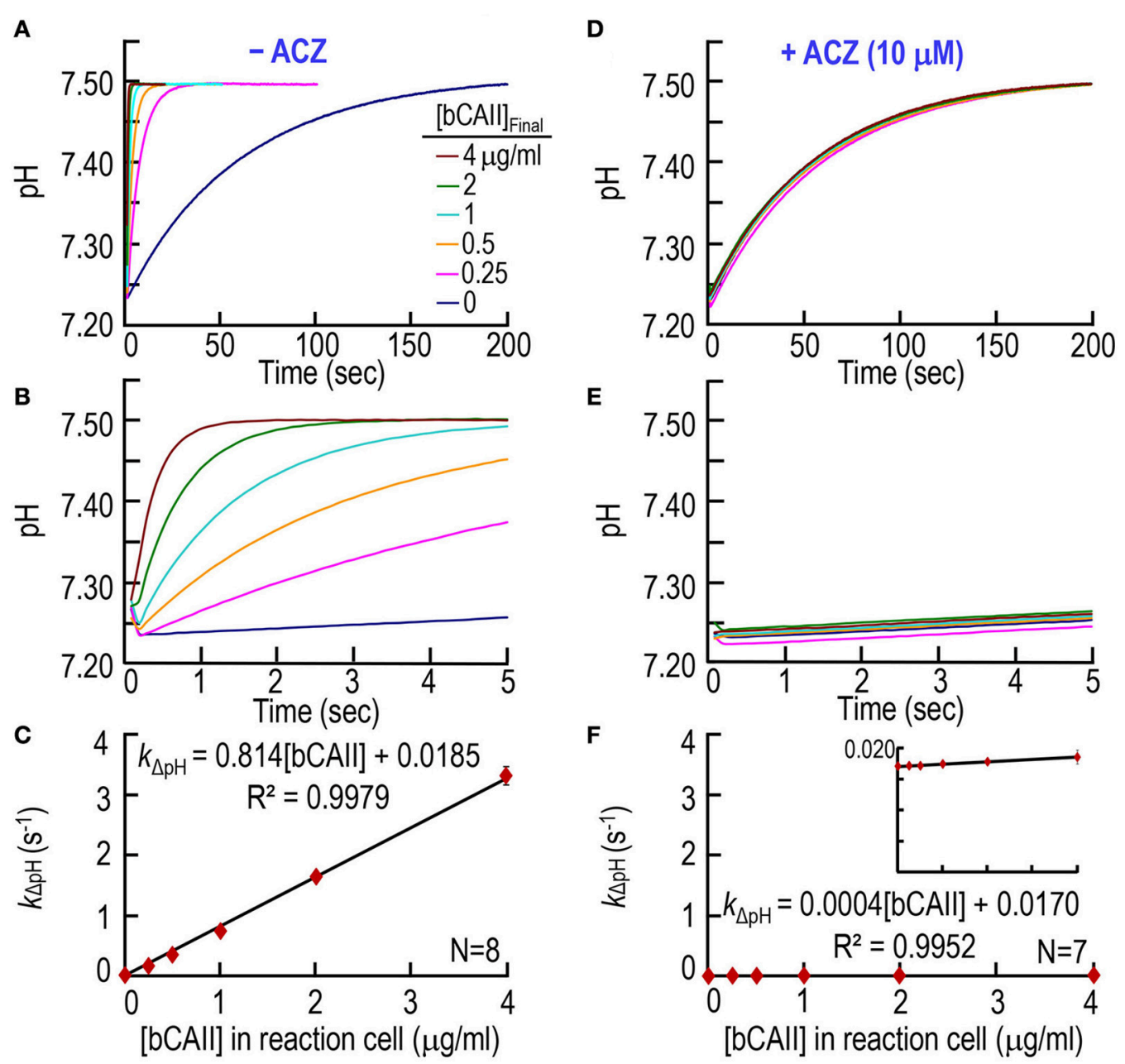

FIGURE 2 | CA assays on purified bovine CA II. (A) Time courses of pH from 0 to $200 \mathrm{~s}$, for concentrations of bCAll ranging from 0 to $4 \mu \mathrm{g} / \mathrm{ml}$ in the reaction cell. We added bCAll to solution A (Table 1) and derived $\mathrm{pH}$-values from the fluorescence of pyranine, added to solution B. (B) Time courses from 0 to $5 \mathrm{~s}$, representing the same records as in (A). (C) Dependence of the rate constant of the $\mathrm{pH}$ change on [bCAll $]_{\mathrm{Rx} \text { Cell }}$. We obtained $k_{\Delta \mathrm{pH}}$-values from non-linear least-squares curve fits of data like those in (A,B). (D) Effect of acetazolamide on time courses of pH from 0 to $200 \mathrm{~s}$ for [bCAll] RxCell ranging from 0 to $4 \mu \mathrm{g} / \mathrm{ml}$. These experiments are like those in (A), except that we added $20 \mu \mathrm{M}$ ACZ to solution B (Table 1). (E) Time courses from 0 to 5 s, representing the same records as in (D). (F) Dependence of $k_{\Delta \mathrm{pH}}$ on $[\mathrm{bCAll}]_{\mathrm{RxCell}}$ in the presence of ACZ. Each data point represents mean $\pm S D$ (error bar not shown if smaller than the symbol). $N$ represents the number of independent experiments, each covering six concentrations $(0-4 \mu \mathrm{g} / \mathrm{ml})$.

to the level of $0.5 \%$ reported by Itada and Forster in their ${ }^{18} \mathrm{O}$ study (Itada and Forster, 1977).

Figures 5B-D show our approach for determining RBC hemolysis in the SF reaction cell. We first determine the relationship between $k_{\Delta \mathrm{pH}}$ and the percent actual hemolysis in an experiment like that in Figure 3C, in which we combine $\mathrm{RBC}$ lysate with saline in various proportions. The ascending light blue line in Figure 5B is the idealized result of such an experiment, and leads to two of the three rate constants needed for the calculation of $\% H$. The brown circle at $0 \%$ actual hemolysis (i.e., $100 \%$ pure saline), represents the uncatalyzed rate constant $\left(k_{\text {uncat }}\right)$ as the overall reaction $\mathrm{HCO}_{3}^{-}+\mathrm{H}^{+} \rightarrow$ $\mathrm{CO}_{2}+\mathrm{H}_{2} \mathrm{O}$ approaches equilibrium under the conditions of our experiments. The red circle at $100 \%$ actual hemolysis (i.e., $100 \% \mathrm{RBC}$ lysate), represents the rate constant ( $\left.k_{\mathrm{RBC}, \text { Lysate }}\right)$ of the overall dehydration reaction, both uncatalyzed and catalyzed by the all of the CA released from our sample of RBC lysate (i.e., the $[\mathrm{CA}]$ corresponding to an $[\mathrm{Hb}]$ of $\sim 2.5 \mu \mathrm{M}$ ). The difference between $k_{\mathrm{RBC} \text {,Lysate }}$ (horizontal red dashed line) and $k_{\text {uncat }}$ (horizontal brown dashed line) represents the rate constant $\left(k_{\text {cat,max }}\right)$ of that portion of the overall reaction catalyzed by all the CA present in our sample of RBCs.

The ascending dashed magenta line in Figure $5 \mathrm{C}$ is the idealized result of an experiment like that in Figure 4C, in which we combine ostensibly intact RBCs with pure $\mathrm{RBC}$ lysate in various proportions. Figure 5C leads to the third rate constant needed for the calculation of percent hemolysis. The green circle at $0 \%$ apparent hemolysis (i.e., $100 \%$ ostensibly intact $\mathrm{RBCs})$, represents the rate constant $\left(k_{\mathrm{RBC}, \text { OstInt }}\right)$ of the overall dehydration reaction, both uncatalyzed and catalyzed by the CA 

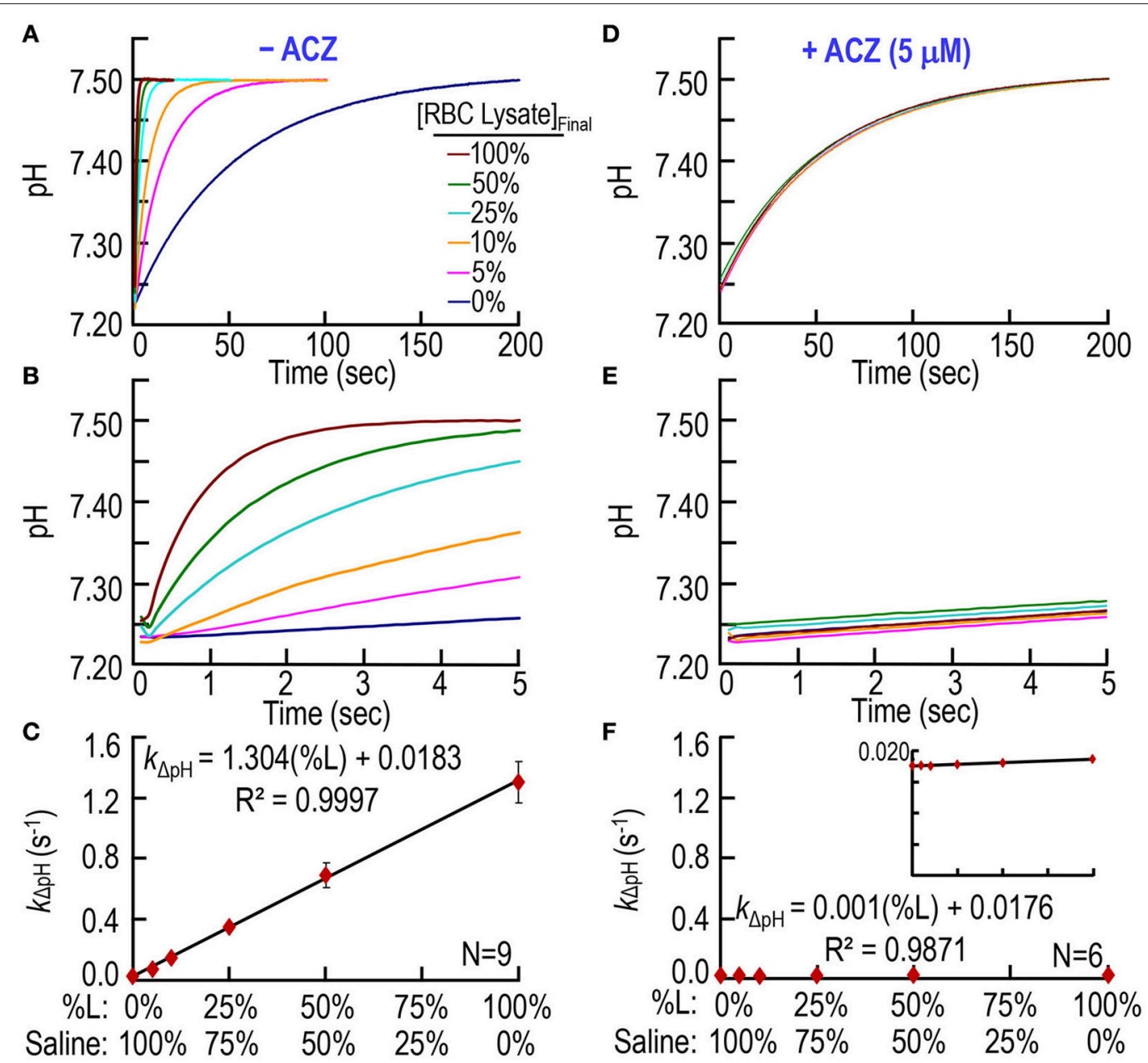

FIGURE 3 | CA assays on lysate from mouse RBCs. (A) Time courses of pH from 0 to 200 s, for different relative amounts of hemolysate. We added RBC lysate to solution $\mathrm{A}$ (Table 1) and derived $\mathrm{pH}$-values from the fluorescence of pyranine, added to solution $\mathrm{B}$. We created all solutions by mixing different ratios of $100 \% \mathrm{RBC}$ lysate $(\% \mathrm{~L}=100 \%)$ and saline. $\% \mathrm{~L}=100 \%$ corresponds to $\sim 2.5 \mu \mathrm{M}$ hemoglobin in the reaction cell. (B) Time courses from 0 to $5 \mathrm{~s}$, representing the same records as in (A). (C) Dependence of the rate constant of the $\mathrm{pH}$ change on the relative amount of RBC lysate. We obtained $k_{\Delta \mathrm{pH}^{-}}$-values from non-linear least-squares curve fits of data like those in (A,B). (D) Effect of acetazolamide on time courses of $\mathrm{pH}$ from 0 to $200 \mathrm{~s}$ for \% ranging from 0 to $100 \%$. These experiments are like those in (A), except that we added $10 \mu \mathrm{M} \mathrm{ACZ}$ to solution B (Table 1). (E) Time courses from 0 to $5 \mathrm{~s}$, representing the same records as in (D). (F) Dependence of $k_{\Delta \mathrm{pH}}$ on $\% \mathrm{~L}$ in the presence of $\mathrm{ACZ}$. Each data point represents mean $\pm S D$ (error bar not shown if smaller than the symbol). $N$ represents the number of independent experiments, each covering six levels of percent RBC lysate (\%L: 0-100\%).

released from the small fraction of RBCs that-unbeknownst to us-are hemolyzed at the time the material is inside the SF reaction cell. The difference between $k_{\mathrm{RBC} \text {, OstInt }}$ (horizontal green dashed line) and $k_{\text {uncat }}$ (horizontal brown dashed line) represents the rate constant $\left(k_{\mathrm{cat}, \mathrm{min}}\right)$ of the portion of the overall reaction catalyzed by that small amount of CA released from ostensibly intact RBCs.

Finally, in Figure 5D-a superimposition of Figures 5A,B, we see the graphical approach for computing the percent actual hemolysis in the SF reaction cell. Starting from the blue circle on the $y$-axis, we move to the right (blue arrow) until we reach the origin of the magenta dashed line, and then move downward (blue arrow) to read the percent actual hemolysis off the light blue $x$-axis. Mathematically, this value is simply $k_{\text {cat, } \min } / k_{\text {cat,max }}$. Using the approach in Figures 5B-D, we calculate that, even if we start with washed RBCs that are only $\sim 0.37 \%$ hemolyzed before they enter the SF device (see above), the total hemolysis is $4.93 \% \pm 1.67 \%(S D)$ in the $\mathrm{SF}$ reaction cell at the end of the experiment (Figure 5E). Thus, the process of performing the SF experiment-loading the RBC mixture into the SF syringes, the flow down the tubing, and the rapid mixing in the SF reaction cell-increases hemolysis.

\section{Comparing RBC Hemolysis Using Fluorescence vs. Absorbance Spectroscopy}

Lastly, we evaluate an alternative approach in which we replace stopped-flow fluorescence spectroscopy (using the dye pyranine) with stopped-flow absorbance spectroscopy (using the dye 


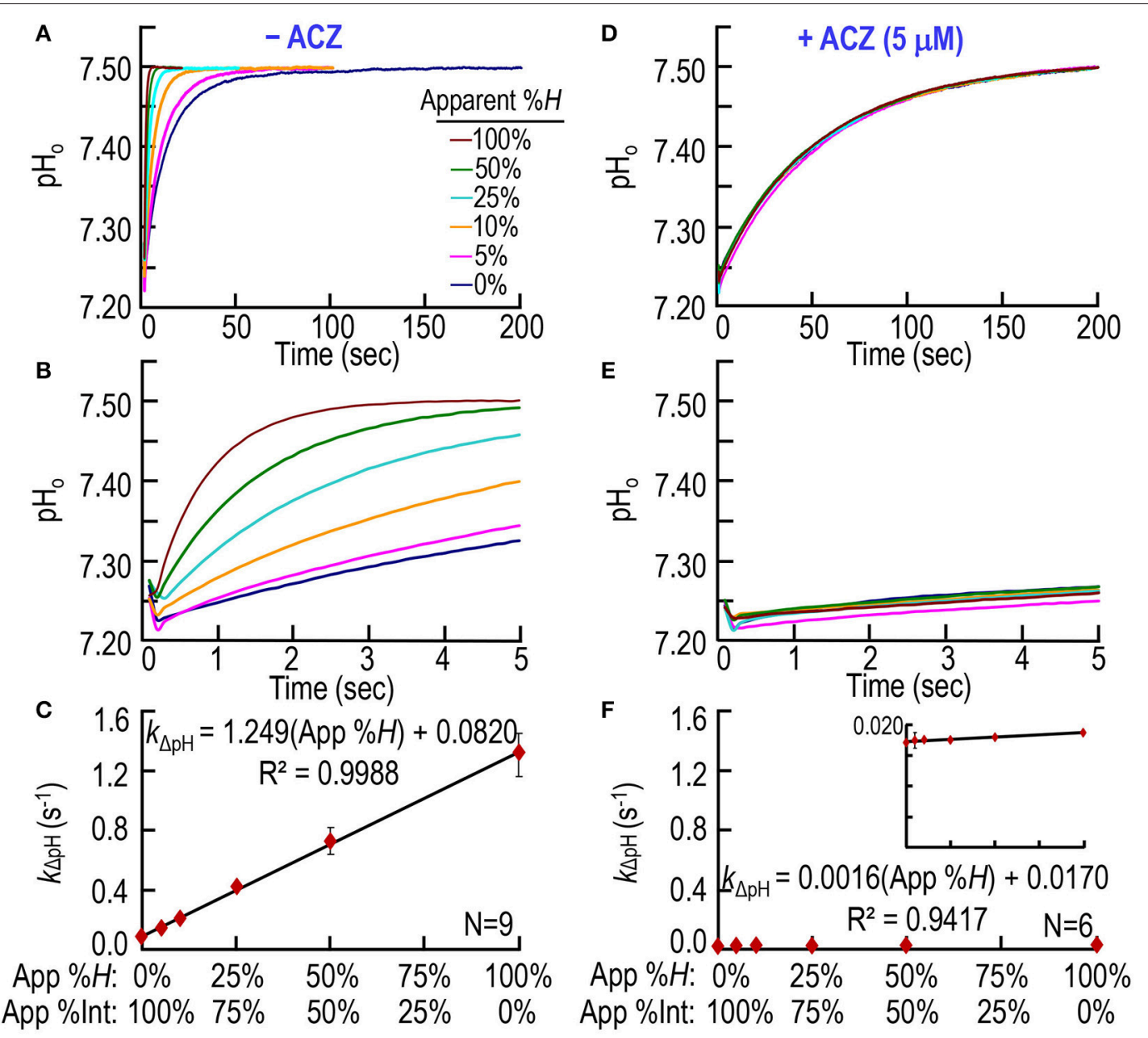

FIGURE 4 | CA assays on mixtures of intact and hemolyzed RBCs. (A) Time courses of pH from 0 to $200 \mathrm{~s}$, for degrees of apparent percent hemolysis ranging from 0 to $100 \%$. We added the hemolysate/RBC mixture to solution A (Table 1) and derived pH-values from the fluorescence of pyranine, added to solution B. We created all solutions by mixing different ratios of $100 \%$ hemolysate and ostensibly $100 \%$ intact RBCs, so that the hemoglobin concentration in the reaction cell was always $\sim 2.5 \mu \mathrm{M}$. (B) Time courses from 0 to $5 \mathrm{~s}$, representing the same records as in (A). (C) Dependence of the rate constant of the pH change on apparent percent hemolysis $(\mathrm{App} \% \mathrm{H})$, which is inversely related to apparent percent intact RBCs (App \%lnt). We obtained $k_{\Delta \mathrm{pH}}$-values from non-linear least-squares curve fits of data like those in (A,B). (D) Effect of acetazolamide on time courses of $\mathrm{pH}$ from 0 to $200 \mathrm{~s}$ for apparent percent hemolysis ranging from 0 to $100 \%$. These experiments are like those in (A), except that we added $10 \mu \mathrm{M}$ ACZ to solution B (Table 1). (E) Time courses from 0 to 5 s, representing the same records as in (D). (F) Dependence of $k_{\triangle \mathrm{pH}}$ on apparent \%H (inversely related to apparent percent intact RBCs) in the presence of ACZ. Each data point represents mean $\pm S D$ (error bar not shown if smaller than the symbol). $N$ represents the number of independent experiments, each covering six hemolysis/RBC mixtures (App \%H: 0-100\%, App \%lnt: 100-0\%).

phenol red). We compare the CA-assay results-fluorescence vs. absorbance-for hemolysis on blood from three mice. As summarized in Figure 6, we find that the estimate of \% hemolysis using the fluorescence approach with pyranine is indistinguishable from that that using the absorbance approach with phenol red.

\section{DISCUSSION}

\section{Comparison of the Present CA Assay with Previous Kinetic Studies}

In the present paper, we describe a simple and rapid assaybased upon the release of CA from RBCs-for determining the degree of hemolysis of RBCs in a SF reaction cell. Moreover, the assay occurs over a time frame and under conditions that are very similar to those of other parallel experiments that generate SF data that are sensitive to percent hemolysis. These other parallel experiments include not only measurements of $\mathrm{Hb}-\mathrm{O}_{2}$ saturation, but also other assays in which the release of a material (e.g., a pH-sensitive dye) previously inside the cell would confound the measurement. Our search of the literature does not identify previous methods for assessing $\% H$ in a SF reaction cell. Others have used the time course of light transmittance (a measure of light scattering) to assess relative hemolysis in assays of the osmotic fragility of RBCs (Didelon et al., 2000; Paździor et al., 2003; Górnicki, 2008). In this earlier approach, one can monitor slowly developing (over tens of seconds) changes in transmittance due to progressive hemolysis, but cannot assign a value to hemolysis perse. 

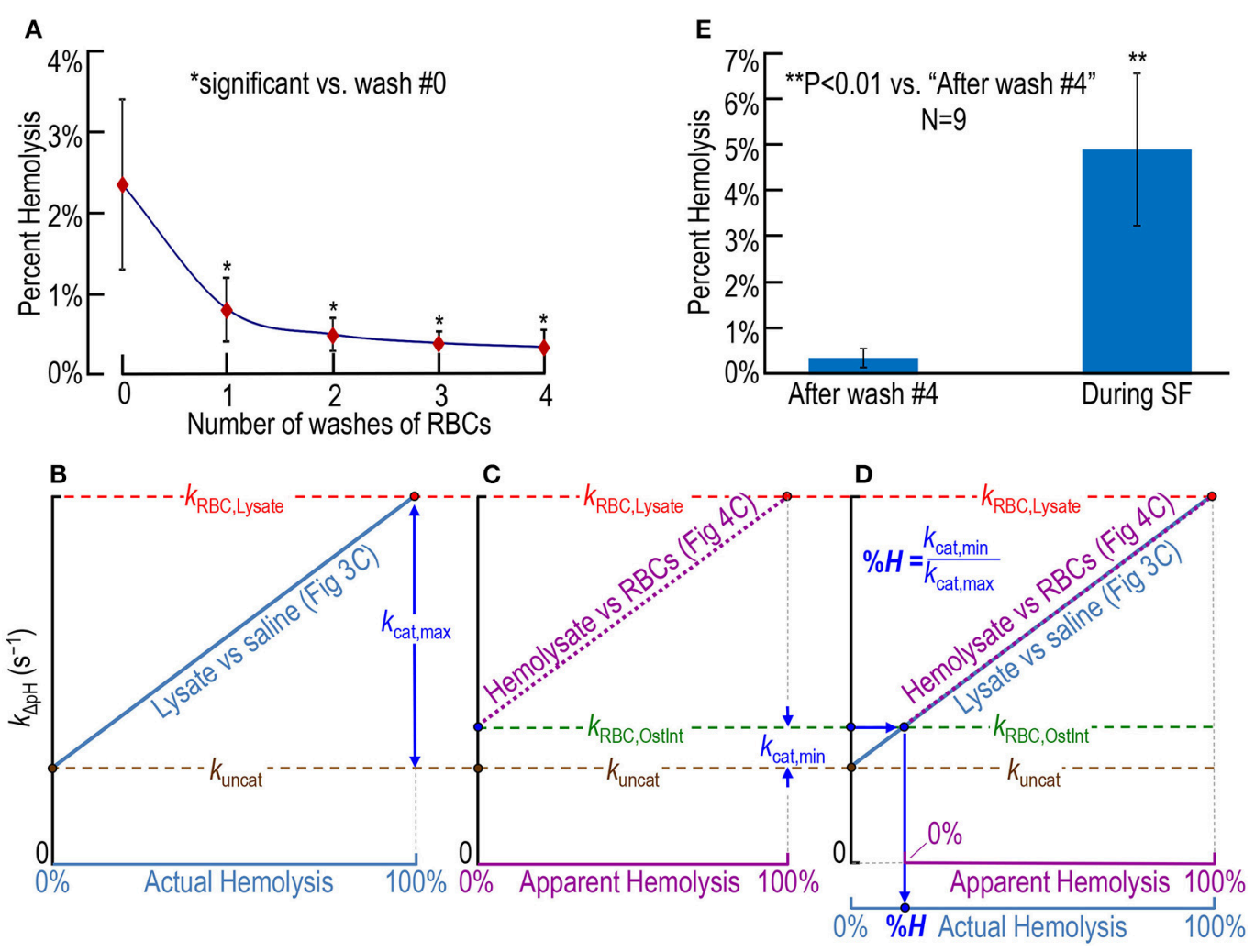

FIGURE 5 | Assessing RBC hemolysis. (A) Estimation of the effect of RBC washes (before stopped-flow experiments) on hemolysis, starting with whole blood containing ostensibly $100 \%$ intact RBCs. Our approaches for computing percent hemolysis before the first wash or after wash \#i (i: 1-4) are described in Section Materials and Methods under "Blood collection." (B-D) Calculation of actual percent hemolysis of ostensibly $100 \%$ intact RBCs during a SF experiment. In (B), we plot the dependence of the rate constant of $\mathrm{pH}$ relaxation on actual hemolysis, the latter being represented by increasing mixing ratios of RBC lysate to saline in Figure 3C. Here, $k_{\text {uncat }}$ represents the uncatalyzed rate constant (i.e., $k_{\Delta \mathrm{pH}}$ without CA), $k_{\mathrm{RBC} \text {,Lysate }}$ represents $k_{\Delta \mathrm{pH}}$ in the presence of $100 \%$ lysate [with (hemoglobin) $\cong 2.5 \mu \mathrm{M}]$, and $k_{\text {cat, max }}$ represents the portion of $k_{\mathrm{RBC}, \text { Lysate }}$ due to the maximally catalyzed CA reaction. That is, $k_{\text {cat,max }}=k_{\mathrm{RBC}, \mathrm{Ly} y a t e}-k_{\text {uncat }}$. In (C), we plot the dependence of $k_{\triangle \mathrm{pH}}$ on apparent hemolysis, the latter being represented increasing mixing ratios of RBC lysate to ostensibly $100 \%$ intact RBCs in Figure 4C. Here, $k_{\mathrm{RBC}}$, Ostlnt represents $k_{\triangle \mathrm{pH}}$ in the presence of ostensibly $100 \%$ intact RBCs, and $k_{\text {cat, min }}$ represents the portion of $k_{\mathrm{RBC}, \text { Ostlnt }}$ due to the minimally catalyzed CA reaction (i.e., that due to the small amount of CA activity released from hemolyzed RBCs in the population of ostensibly $100 \%$ intact RBCs). That is, $k_{\text {cat,min }}=k_{\mathrm{RBC}, \text { Ostlnt }}-k_{\text {uncat }}$. In (D), we overlay the plots in (B,C). The percent hemolysis $(\% H)$ of RBCs during an SF experiment is the quotient $k_{\text {cat,min }} / k_{\text {cat,max }}$. One may obtain the same answer graphically by following, first, the horizontal arrow from the $y$-axis and, then, the vertical arrow to \%H. (E) Comparison of \%H of ostensibly 100\%-intact RBCs after four washes (i.e., before the SF experiment) and during SF experiments. The value for "after wash \#4" in (E) is the same as for $i=4$ in (A) (nine mice). The value for "During SF" in (E) is the mean for the same nine mice. For each mouse, we obtained plots that were the equivalent of those in (B) through (D), and computed a \% $H$ for that mouse. Each data point represents the mean $\pm S D$ (lower error bar not shown if it overlaps with $x$-axis tick mark). Differences are evaluated using the two-tailed paired student's $t$-test. In (A), *indicates statistical significance-after applying the Holm-Bonferroni correction-for comparisons to wash \#0 of wash \#1 $(P=0.0013)$, wash \#2 $(P=0.00016)$, wash \#3 $\left(P=8.4 \times 10^{-5}\right)$, and wash \#4 $\left(P=7.2 \times 10^{-5}\right)$. None of the other comparisons in (A) yielded statistical significance. $N$ represents the number of mice from which we obtained blood.

In the present study, we obtain a single value of hemolysis measured over several tens of seconds, but cannot directly address the time course of hemolysis per se. However, because the time courses of $\mathrm{pH}$ in Figures 4A,B are exponential beginning no later than $\sim 0.3 \mathrm{~s}$ after the stoppage of flow, we can conclude that the hemolysis was virtually complete by this time. In other words, the degree of hemolysis that we measure (right bar Figure 5E) presumably reflects the aggregate hemolysis that occurs to some extent in the preparation of the blood (left bar Figure 5E) but mainly in the syringes, tubing, and the first moments in the reaction cell of the SF device.

Others have previously assessed $\mathrm{CA}$ activity using $\mathrm{pH}-$ based SF approaches (Gibbons and Edsall, 1963, 1964; Ho and Sturtevant, 1963; Kernohan, 1964, 1965; Khalifah, 1971; Wistrand et al., 1975; Pocker and Bjorkquist, 1977; Crandall and O'Brasky, 1978; DeGrado et al., 1982; Sanyal et al., 1982; Baird et al., 1997; Shingles and Moroney, 1997; Wang et al., 2010) with tissue homogenates or cell-free enzyme preparations. The ionic conditions in these earlier studies would have been inappropriate for living cells. By definition, these earlier studies involved monitoring $\mathrm{pH}$ as the solution in the SF reaction cell transitioned from an OOE state toward an equilibrium state. However, fundamental differences between our approach and those of others are that the present assay provides:

1. Solutions $\mathrm{A}$ and $\mathrm{B}$ of moderate and defined $\mathrm{pH}$-values. Regarding the previous SF studies of CA activity, only one 


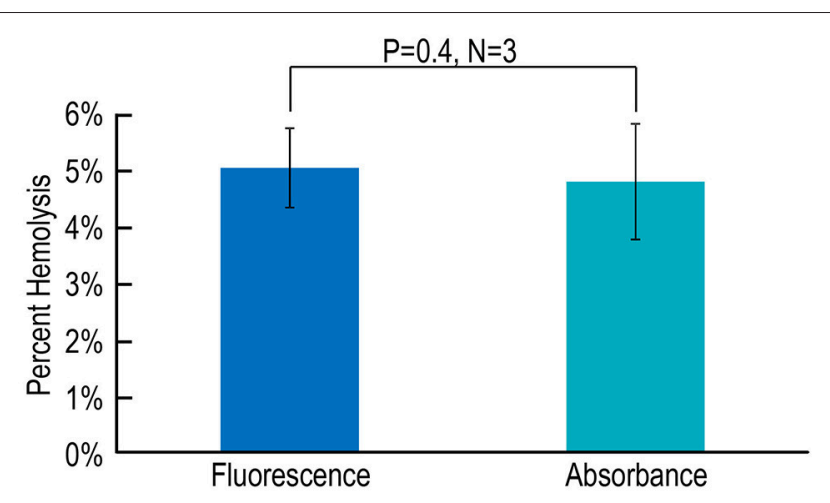

FIGURE 6 | Assessing hemolysis by fluorescence vs. absorbance spectroscopy. Each $N$ represents blood from one mouse, analyzed in parallel using both a fluorescence-based assay with pyranine and an

absorbance-based assay with phenol red. Values are means $\pm S D$, evaluated using a two-tailed paired student's t-test.

(Shingles and Moroney, 1997) reports SF time courses of $\mathrm{pH}$ per se, and only one (Shingles and Moroney, 1997) provides sufficient detail (including $\mathrm{pH}$-values of both solution A and solution $\mathrm{B}$ ) to permit replication of the work. In our assay, both solution $\mathrm{A}(\mathrm{pH}$ 7.03) and solution $\mathrm{B}(\mathrm{pH} 8.41)$ have relatively moderate $\mathrm{pH}$-values, thereby ensuring that the RBCs are under near-physiological electrolyte conditions throughout the assay. Even though the CA enzyme or RBCs are in the near-neutral solution A in our assay, it is important that solution $\mathrm{B}$ not have an extreme $p$-value. Earlier OOE work (Zhao et al., 1995) provided evidence of transient microdomains upon mixing of solutions A and B (i.e., the enzyme or cells in solution A could come into direct contact with relatively undiluted solution $\mathrm{B}$ ). In principle, we could have designed a solution $\mathrm{B}$ with a lower $\mathrm{pH}$. A consequence (all else being equal) would have been a smaller $\Delta \mathrm{pH}$ during the relaxation phase of the experiment. However, the signalto-noise resolution of our assays was sufficiently high that we could have still obtained reliable $k_{\Delta \mathrm{pH}}$ data, even with a smaller $\Delta \mathrm{pH}$.

2. Predictable $\mathrm{pH}$-values in the $\mathrm{SF}$ reaction cell. Our OOE approach generates, upon mixing of solutions $\mathrm{A}$ and $\mathrm{B}$, predictable $\mathrm{pH}$-values at time zero, and predictable $\mathrm{pH}$ time courses (simulations not shown).

Although the assay in the present study is based on the reaction $\mathrm{HCO}_{3}^{-}+\mathrm{H}^{+} \stackrel{\mathrm{CA}}{\rightarrow} \mathrm{CO}_{2}+\mathrm{H}_{2} \mathrm{O}$ (equivalent to the dehydration of $\mathrm{H}_{2} \mathrm{CO}_{3}$ ) and thus produces a $\mathrm{pH}$ increase, we could have constructed solutions $\mathrm{A}$ and $\mathrm{B}$ so that, upon solution mixing in the reaction cell, the OOE state would have led to the opposite reactions (equivalent to the hydration of $\mathrm{CO}_{2}$ ) and thus a $\mathrm{pH}$ decrease.

\section{Experiments at $10^{\circ} \mathrm{C}$}

Transport events across the RBC membrane can be extremely fast. In the present study, we chose $10^{\circ} \mathrm{C}$ to match the temperature in parallel work on $\mathrm{O}_{2}$ fluxes. This temperature, although considerably less than typical physiological temperatures of mammals, is nevertheless higher than those used by other investigators in RBC-transport studies, where it is customary to lower $\mathrm{RBC}$ temperatures to $5^{\circ} \mathrm{C}$ or even $0^{\circ} \mathrm{C}$ (Kimzey and Willis, 1971; Lowe and Walmsley, 1986; Jensen et al., 2001; Jennings, 2005).

\section{CAs in RBCs}

The 14 mammalian $\alpha$ CAs (Sly and $\mathrm{Hu}, 1995$; Purkerson and Schwartz, 2007; Supuran, 2016) are zinc-containing metalloenzymes that are expressed in virtually every cell of the body. They are broadly divided into four subgroups: the cytosolic [a] CA I, II, III, VII, and VIII; [b] the mitochondrial CA V; [c] the secreted CA VI; and [d] the membrane-bound CAs IV, IX, XII, and XIV (Sly and Hu, 1995; Parkkila et al., 1996; Karhumaa et al., 2000; Kummola et al., 2005; Scheibe et al., 2006). A proteomics study identified CA I, II, and III in RBC cytoplasm (Kakhniashvili et al., 2004). In human erythrocytes, CA II is a high-activity isozyme; CA I contributes only half of the total CA activity although it is almost six times as abundant as CA II (Khalifah, 1971; Dodgson et al., 1988; Sly and Hu, 1995). CA III-the activity of which is reported to be only $0.03-1 \%$ that of CA II (Sly and Hu, 1995; Purkerson and Schwartz, 2007)_-is expressed mainly in skeletal muscle and adipose tissue, but at lower levels in other tissues, including RBCs (Sly and Hu, 1995; Kakhniashvili et al., 2004; Pasini et al., 2006; Goodman et al., 2007). Within the $\mathrm{RBC}$, these CA enzymes are critically important for converting metabolically produced $\mathrm{CO}_{2}$ to $\mathrm{HCO}_{3}^{-}\left(\mathrm{CO}_{2}+\mathrm{H}_{2} \mathrm{O} \stackrel{\mathrm{CA}}{\rightarrow} \mathrm{HCO}_{3}^{-}\right.$ $+\mathrm{H}^{+}$) while the $\mathrm{RBC}$ is in systemic capillaries, and then-after the $\mathrm{RBC}$ has transited to the lung-for reconverting the $\mathrm{HCO}_{3}^{-}$to $\mathrm{CO}_{2}\left(\mathrm{HCO}_{3}^{-}+\mathrm{H}^{+} \stackrel{\mathrm{CA}}{\rightarrow} \mathrm{CO}_{2}+\mathrm{H}_{2} \mathrm{O}\right)$ in the pulmonary capillaries for elimination in the exhaled air.

Although a mass-spectrometry analysis study reveals no evidence of membrane-associated CAs in RBCs (Low et al., 2002), immunological and kinetic evidence points to a tiny amount of CA IV, presumably on the outer surface, that could contribute $0.2 \%$ of total CA activity (Wistrand et al., 1999). If this CA IV estimate for RBCs is correct, then $0.2 / 4.93 \% \cong 4 \%$ of the estimated $\% H$ of $4.93 \%$ (Figure $5 \mathrm{E}$ ) in the SF reaction cell could reflect the presence of extracellular-facing CA IV rather than hemolysis per se (i.e., we may slightly overestimate the degree of hemolysis).

\section{Evidence for the Validity of the Present CA Assay}

The following analyses of our data provide evidence that our CA assay behaves in a stable and precise way:

1. Linear relationship of $k_{\Delta p H}$ vs. [bCAII]. For the experiments in Figure 2, we chose a commercial preparation of bovine CA II, purified from RBCs, because bCAII is the most readily obtainable and reliable CA preparation. As expected, $k_{\Delta \mathrm{pH}}$-which reflects the equilibration of all reactions as $\mathrm{pH}$ rises from $\sim 7.25$ to 7.50 -rises linearly with increasing concentrations of CA II (Figure 2C). Thus, we hypothesized that we could exploit the release of CAs from RBCs to quantitate the degree of hemolysis. 
2. Linear relationship of $k_{\Delta p H}$ vs. percent lysate. For the experiments in Figure 3, we chose to work with the lysate of a preparation of mouse RBCs having a [Hb] of $\sim 2.5 \mu \mathrm{M}$ in the reaction cell-the starting material for the ostensibly intact RBCs in Figure 4. As expected, $k_{\Delta \mathrm{pH}}$ in Figure 3C rises linearly with increasing $\% \mathrm{~L}$ (Figure $3 \mathrm{C}$ ), reflecting the increasing concentration of CAs.

3. Linear relationship of $k_{\Delta p H}$ vs. percent hemolysis. For the experiments in Figure 4, we dilute ostensibly intact RBCs with pure $\mathrm{RBC}$ lysate to maintain a $[\mathrm{Hb}]$ of $\sim 2.5 \mu \mathrm{M}$ in the reaction cell. Note that pyranine [a] permeates cell membranes poorly (Shingles and Moroney, 1997; Avnir and Barenholz, 2005; Han and Burgess, 2010) and [b] is in contact with the $\mathrm{RBCs}$ for only a few seconds. We find that $\mathrm{pH}_{\mathrm{o}}$ rises with a near-exponential time course in Figures $4 \mathbf{A}, \mathbf{B}$, and that the resulting $k_{\Delta \mathrm{pH}}$-values rise linearly with increasing $\% H$ (Figure 4C). If a substantial fraction of total pyranine were slowly entering $\mathrm{RBCs}$ (which undergo a $\mathrm{pH}$ decrease as $\mathrm{CO}_{2}$ enters and $\mathrm{HCO}_{3}^{-}$exits via $\mathrm{AE} 1$ ), the $\mathrm{pH}_{\mathrm{o}}$ trajectory would have had a second phase that reflected the evolving contribution of the $\mathrm{pH}$ inside the RBCs. Thus, we can conclude that the CA inside the $\mathrm{RBC}$ is not appreciably accessible to the dye under the conditions of our experiments.

4. Consistency of 100\% lysate/hemolysis points in Figures 3C, 4C. In Figure 3C, the best-fit value for $k_{\Delta \mathrm{pH}}$ when $\% \mathrm{~L}=$ $100 \%$ is $1.304 \times 100 \%+0.0183=1.322 \mathrm{~s}^{-1}$. In Figure 4C, the comparable value for $k_{\Delta \mathrm{pH}}$ when $\% H=100 \%$ is 1.249 $\times 100 \%+0.0820=1.331 \mathrm{~s}^{-1}$. These two values differ by $<0.7 \%$, indicating the internal consistency of the two data sets.

5. CA activity of mouse RBCs. From the previous paragraph, we see that the $k_{\Delta \mathrm{pH}}$ in the $100 \%$ mouse RBC lysate (Figure 3C) is $1.322 \mathrm{~s}^{-1}$. From the line of best fit in Figure 2C, we see that a mouse RBC lysate value of $1.322 \mathrm{~s}^{-1}$ corresponds to a $[\mathrm{bCAII}]_{\mathrm{RxCell}}$ of $1.6 \mu \mathrm{g} / \mathrm{ml}$. Given a $\mathrm{MW}$ of 29,000 Da for bCAII, we calculate that the total CA activity (from mouse RBCs) in the reaction cell (representing 100\% lysate) is equivalent to that of $\sim 0.055 \mu \mathrm{M}$ bCAII. Although we set mouse $[\mathrm{Hb}]_{\mathrm{RxCell}}$ to $2.5 \mu \mathrm{M}$ in Figure $3 \mathrm{C}$, the mean corpuscular hemoglobin concentration (MCHC) for wild-type mouse RBCs that we obtained in a parallel study is $31.7 \mathrm{~g} / \mathrm{dL}$, which corresponds to a $[\mathrm{Hb}]_{\mathrm{i}}$ of $\sim 4.9 \mathrm{mM}$. Thus, the $[\mathrm{Hb}]$ in the reaction cell of the present study represents a $\sim 1967$ fold dilution of cytosolic $\mathrm{Hb}$. We calculate that the total CA contributed by the mouse RBCs behaves as if it were $\sim 109 \mu \mathrm{M}$ bCAII. We are not aware of data on the CA content of mouse RBCs. However, the mean of three values for the CAII/Hb ratio of human RBCs (Tashian and Carter, 1976; Ali Akbar and Brown, 1996), together with an assumed $[\mathrm{Hb}]_{\mathrm{i}}$ of $5 \mathrm{mM}$, leads to $[\mathrm{CAII}]_{\mathrm{i}}$ of $\sim 20 \mu \mathrm{M}$ for human RBCs. Thus, our computed CA activity of mouse RBCs (equivalent to $\sim 109 \mu \mathrm{M}$ bCAII) is $\sim 5$-fold higher than the $[\mathrm{CAII}]_{\mathrm{i}}$ of human RBCs. Considering that CAII contributes only about half of the total CA activity of human RBCs, and that the purchased bCAII may have a lower specific activity than the total CA released from freshly lysed mouse RBCs, we conclude that the equivalent concentration of $\sim 109 \mu \mathrm{M}$ bCAII is reasonable.

6. Consistency of slopes in Figures 3C, 4C. As illustrated by the analysis in Figures 5B-E, the difference between the slopes of the best-fit lines in Figure 3C (i.e., $1.304 \mathrm{~s}^{-1} / \% \mathrm{~L}$ ) and Figure 4C (i.e., $1.249 \mathrm{~s}^{-1} / \% H$ ) is almost completely accounted for by the actual \%Hemolysis of ostensibly intact RBCs (i.e., $4.93 \%$ ). That is, $1.304 \times 95.07 \%=1.240$, which is only $\sim 0.7 \%$ lower than 1.249.

7. Comparison of $y$-intercepts in Figures 3C, 4C. In Figure 3C, the best-fit value for the $y$-intercept (i.e., $\% \mathrm{~L}=0 \%$ ) is 0.0183 $\mathrm{s}^{-1}$, which is the rate constant for the uncatalyzed reactions. In Figure 4C, the comparable best-fit y-intercept is 0.0820 $\mathrm{s}^{-1}$, which is the aggregate $k_{\Delta \mathrm{pH}}$ for the uncatalyzed and catalyzed reactions. The difference $0.0820 \mathrm{~s}^{-1}-0.0183$ $\mathrm{s}^{-1}=0.0637 \mathrm{~s}^{-1}$, which represents the mean portion of $k_{\Delta \mathrm{pH}}$ attributable to the extracellular CA activity of ostensibly intact RBCs. Dividing this residual y-intercept by the best-fit slope in Figure 3C yields the mean $\% H$ of ostensibly intact RBCs: $\left(0.0637 \mathrm{~s}^{-1}\right) /\left(1.304 \mathrm{~s}^{-1} / \% \mathrm{~L}\right)=4.9 \%$. Performing the computation mouse by mouse, we obtain $4.93 \pm 1.67 \%(N=$ 9). The value, compared to the pre-SF value of $0.37 \pm 0.21 \%$ indicates that a small amount of ostensibly intact RBCs are in fact hemolyzed in the SF reaction cell.

8. Effect of ACZ in Figures 2D-F, 3D-F, 4D-F. In all of our studies, ACZ collapsed all $\mathrm{pH}$ trajectories to virtually the same time course-and the same $\mathrm{pH}$ range-as the uncatalyzed (i.e., slowest) reactions in Figures 2A-C, 3A-C. However, we notice that the best-fit $y$-intercepts in Figures $2 \mathrm{~F}, 3 \mathbf{F}, \mathbf{4 F}$ are all very slightly lower than those in Figures 2C, 3C. An analysis of the $[\mathrm{bCAII}]_{\mathrm{RxCell}}=0$ points in Figure $2 \mathrm{C}\left(k_{\Delta \mathrm{pH}}\right.$ $\left.=0.0185 \pm 0.0014 \mathrm{~s}^{-1}\right)$ and Figure $2 \mathrm{~F}\left(k_{\Delta \mathrm{pH}}=0.0170 \pm\right.$ $\left.0.0005[S D] \mathrm{s}^{-1}\right)$ is a statistically significant difference $(P=$ 0.028 , two-tailed, unpaired $t$-test). For the $\% \mathrm{~L}=0$ points in Figure 3C $\left(k_{\Delta \mathrm{pH}}=0.0183 \pm 0.0019 \mathrm{~s}^{-1}\right)$ and Figure 3F $\left(k_{\Delta \mathrm{pH}}=0.0176 \pm 0.0007 \mathrm{~s}^{-1}\right)$, the difference is not statistically significant $(P=0.37$, two-tailed, unpaired $t$-test). For the $\% H$ $=0$ point in Figure 4F, $k_{\Delta \mathrm{pH}}=0.0170 \pm 0.0006$. Although it is possible that $\mathrm{ACZ}$ affects the pyranine dye, we suggest that it is more likely that, despite extensive washing between samples, a small amount of CA remains adsorbed to the surface of the reaction cell. Such a small amount of adsorbed CA would not affect our calculation of $\% H$ of ostensibly intact RBCs from a mouse because the uncatalyzed $k_{\Delta \mathrm{pH}}$-value that we subtract is the value obtained in $\% \mathrm{~L}=0$ from an experiment like that in Figure 3B (not the one with ACZ in Figures 3E or $4 \mathrm{E})$.

9. Phenol red vs. pyranine in Figure 6. We observed that our novel CA/hemolysis assay-applied to the same murine RBC samples-yields virtually identical results with two different dyes, one studied by stopped-flow fluorescence and the other by stopped-flow absorbance spectroscopy. The absorbancespectroscopy method with a non-fluorescent dye would be particularly useful when the system contains materials with significant fluorescence. 


\section{CONCLUSION}

Our novel CA assay with OOE solutions makes it possible to assess hemolysis under approximately physiological conditions, and to do so over a predictable $\mathrm{pH}$ range. The increase in percent hemolysis between the time of loading samples into the SF machine $(<0.4 \%)$ and during our SF assay $(\sim 4.9 \%)$ presumably due to mechanical disruption of a subpopulation of susceptible RBCs during rapid mixing. This assay is easy to perform, highly sensitive and precise, and in principle could be implemented in either the direction $\mathrm{HCO}_{3}^{-}+\mathrm{H}^{+} \stackrel{\mathrm{CA}}{\longrightarrow} \mathrm{CO}_{2}+$ $\mathrm{H}_{2} \mathrm{O}$ (equivalent to $\mathrm{H}_{2} \mathrm{CO}_{3}$ dehydration, as in the present study) or the direction $\mathrm{CO}_{2}+\mathrm{H}_{2} \mathrm{O} \stackrel{\mathrm{CA}}{\rightarrow} \mathrm{HCO}_{3}^{-}+\mathrm{H}^{+}$(equivalent to $\mathrm{CO}_{2}$ hydration). Moreover, it is readily amenable to miniaturization and automation using microfluidics. Applied to ostensibly intact RBCs, the assay could report RBC fragility and thus provide diagnostic insight in fresh blood from patients. Besides RBCs, the lysis assay could detect disruption within a SF device of many other cell types or membrane vesicles with entrapped CA. The underlying CA assay-applied to fluids such as blood plasma, tissue-culture media, and organ perfusates-could assess cell lysis in a wide range of cells or tissues previously in contact with these fluids. Applications could include quantitating RBC storage lesions before performing blood transfusions, evaluating the health of cells in culture or during flow cytometry, and assessing the health of organs for transplantation. Together with a panel of specific CA inhibitors, our assay also could quantitate multiple different CA subtypes within a sample, and identify the lysed cells from which they came.

\section{REFERENCES}

Aliakbar, S., and Brown, P. R. (1996). Measurement of human erythrocyte CAI and CAII in adult, newborn, and fetal blood. Clin. Biochem. 29, 157-164. doi: 10.1016/0009-9120(95)02021-7

Avnir, Y., and Barenholz, Y. (2005). pH determination by pyranine: medium-related artifacts and their correction. Anal. Biochem. 347, 34-41. doi: 10.1016/j.ab.2005.09.026

Baird, T. T., Waheed, A., Okuyama, T., Sly, W. S., and Fierke, C. A. (1997). Catalysis and inhibition of human carbonic anhydrase IV. Biochem. Mosc. 36, 2669-2678. doi: 10.1021/bi962663s

Barlow, C. H., Kelly, K. A., and Kelly, J. J. (1992). Simultaneous determination of hemoglobin and myoglobin oxygen binding curves by spectral curve fitting. Appl. Spectrosc. 46, 758-763. doi: 10.1366/0003702924124763

Boyarsky, G., Ganz, M. B., Sterzel, R. B., and Boron, W. F. (1988). pH regulation in single glomerular mesangial cells. I. Acid extrusion in absence and presence of $\mathrm{HCO}_{3}^{-}$. Am. J. Physiol. 255, C844-C856.

Brinkman, R. (1933). The occurrence of carbonic anhydrase in lower marine animals. J. Physiol. 80, 171-173. doi: 10.1113/jphysiol.1933.sp003079

Chance, B. (1950). The reactions of catalase in the presence of the notatin system. Biochem. J. 46, 387-402. doi: 10.1042/bj0460387

Crandall, E. D., and O’Brasky, J. E. (1978). Direct evidence of participation of rat lung carbonic anhydrase in $\mathrm{CO}_{2}$ reactions. J. Clin. Invest. 62, 618-622. doi: 10.1172/JCI109168

DeGrado, W. F., Musso, G. F., Lieber, M., Kaiser, E. T., and Kézdy, F. J. (1982). Kinetics and mechanism of hemolysis induced by melittin and by a synthetic melittin analogue. Biophys. J. 37, 329-338. doi: 10.1016/S0006-3495(82)84681-X

\section{AUTHOR CONTRIBUTIONS}

PZ and RG have contributed equally to this work. PZ, RG, and $\mathrm{WB}$ contributed to experimental design. PZ and RG performed experiments and analyzed data. PZ, RG, and WB wrote the manuscript. All authors approved the final version to be published.

\section{FUNDING}

This work was supported by grants from the Office of Naval Research (N00014-11-1-0889, N00014-14-1-0716, and N0001415-1-2060 to WB). RG was supported by a fellowship grant from the Office of Naval Research (N00014-12-1-0326).

\section{ACKNOWLEDGMENTS}

We acknowledge Dr. Mark D. Parker suggesting that the hemolysis assay be based on the measurement of a released enzyme activity. We thank Dr. Rossana Occhipinti for helpful discussions on the kinetics of the equilibration of the reactions in the stopped-flow reaction cell, Dr. Ahlam Salameh for helpful discussions on the design of the out-of-equilibrium solutions, and Dr. Fraser Moss for advice on the statistics. We thank computer engineer Dale Huffman for technical and computer support. We also thank laboratory manager Gerald T. Babcock for general assistance, and both him and Thomas S. Radford for their help with our wild-type mouse colony. WB gratefully acknowledges the support of the Myers/Scarpa endowed chair.

Didelon, J., Mazeron, P., Muller, S., and Stoltz, J. F. (2000). Osmotic fragility of the erythrocyte membrane: characterization by modeling of the transmittance curve as a function of the $\mathrm{NaCl}$ concentration. Biorheology 37, 409-416.

Dodgson, S. J., Forster, R. E. II, Sly, W. S., and Tashian, R. E. (1988). Carbonic anhydrase activity of intact carbonic anhydrase II-deficient human erythrocytes. J. Appl. Physiol. 65, 1472-1480.

Gibbons, B. H., and Edsall, J. T. (1963). Rate of hydration of carbon dioxide and dehydration of carbonic acid at 25 degrees. J. Biol. Chem. 238, 3502-3507.

Gibbons, B. H., and Edsall, J. T. (1964). Kinetic studies of human carbonic anhydrases B and C. J. Biol. Chem. 239, 2539-2544.

Goodman, S. R., Kurdia, A., Ammann, L., Kakhniashvili, D., and Daescu, O. (2007). The human red blood cell proteome and interactome. Exp. Biol. Med. 232, 1391-1408. doi: 10.3181/0706-MR-156

Górnicki, A. (2008). The hemolysis kinetics of psoriatic red blood cells. Blood Cells Mol. Dis. 41, 154-157. doi: 10.1016/j.bcmd.2008.04.003

Han, J., and Burgess, K. (2010). Fluorescent indicators for intracellular pH. Chem. Rev. 110, 2709-2728. doi: 10.1021/cr900249z

Hernández, S. E., Rodríguez, V. D., Pérez, J., Martín, F. A., Castellano, M. A., and Gonzalez-Mora, J. L. (2009). Diffuse reflectance spectroscopy characterization of hemoglobin and intralipid solutions: in vitro measurements with continuous variation of absorption and scattering. J. Biomed. Opt. 14:034026. doi: 10.1117/1.3149864

Ho, C., and Sturtevant, J. M. (1963). The kinetics of the hydration of carbon dioxide at 25 degrees. J. Biol. Chem. 238, 3499-3501.

Hollingworth, S., and Baylor, S. M. (1990). Changes in phenol red absorbance in response to electrical stimulation of frog skeletal muscle fibers. J. Gen. Physiol. 96, 473-491. doi: 10.1085/jgp.96.3.473 
Holm, S. (1979). A simple sequentially rejective multiple test procedure. Scand. J. Stat. 6, 65-70.

Itada, N., and Forster, R. E. (1977). Carbonic anhydrase activity in intact red blood cells measured with ${ }^{18} \mathrm{O}$ exchange. J. Biol. Chem. 252, 3881-3890.

Jennings, M. L. (2005). Evidence for a second binding/transport site for chloride in erythrocyte anion transporter AE1 modified at glutamate 681. Biophys. J. 88, 2681-2691. doi: 10.1529/biophysj.104.056812

Jensen, F. B., Wang, T., and Brahm, J. (2001). Acute and chronic influence of temperature on red blood cell anion exchange. J. Exp. Biol. 204, 39-45.

Kakhniashvili, D. G., Bulla, L. A. Jr. and Goodman, S. R. (2004). The human erythrocyte proteome: analysis by ion trap mass spectrometry. Mol. Cell. Proteomics 3, 501-509. doi: 10.1074/mcp.M300132-MCP200

Karhumaa, P., Parkkila, S., Türeci, Ö., Waheed, A., Grubb, J. H., Shah, G., et al. (2000). Identification of carbonic anhydrase XII as the membrane isozyme expressed in the normal human endometrial epithelium. Mol. Hum. Reprod. 6, 68-74. doi: 10.1093/molehr/6.1.68

Kernohan, J. C. (1964). The activity of bovine carbonic anhydrase in imidazole buffers. Biochim. Biophys. Acta 81, 346-356.

Kernohan, J. C. (1965). The pH-active curve of bovine carbonic anhydrase and its relationship to the inhibition of the enzyme by anions. Biochim. Biophys. Acta 96, 304-317. doi: 10.1016/0005-2787(65)90593-9

Kernohan, J. C., and Roughton, F. J. (1968). Thermal studies of the rates of the reactions of carbon dioxide in concentrated haemoglobin solutions and in red blood cells. A. The reactions catalysed by carbonic anhydrase. B. The carbamino reactions of oxygenated and deoxygenated haemoglobin. J. Physiol. 197, 345-361. doi: 10.1113/jphysiol.1968.sp008563

Khalifah, R. G. (1971). The carbon dioxide hydration activity of carbonic anhydrase. I. Stop-flow kinetic studies on the native human isoenzymes B and C. J. Biol. Chem. 246, 2561-2573.

Kimzey, S. L., and Willis, J. S. (1971). Temperature adaptation of active sodiumpotassium transport and of passive permeability in erythrocytes of ground squirrels. J. Gen. Physiol. 58, 634-649. doi: 10.1085/jgp.58.6.634

Kummola, L., Hämäläinen, J. M., Kivelä, J., Kivelä, A. J., Saarnio, J., Karttunen, T., et al. (2005). Expression of a novel carbonic anhydrase, CA XIII, in normal and neoplastic colorectal mucosa. BMC Cancer 5:41. doi: 10.1186/1471-2407-5-41

Low, T. Y., Seow, T. K., and Chung, M. C. (2002). Separation of human erythrocyte membrane associated proteins with one-dimensional and two-dimensional gel electrophoresis followed by identification with matrix-assisted laser desorption/ionization-time of flight mass spectrometry. Proteomics 2, 1229-1239. doi: 10.1002/16159861(200209)2:9<1229::AID-PROT1229>3.0.CO;2-N

Lowe, A. G., and Walmsley, A. R. (1986). The kinetics of glucose transport in human red blood cells. Biochim. Biophys. Acta 857, 146-154. doi: 10.1016/0005-2736(86)90342-1

Meldrum, N. U., and Roughton, F. J. (1933). Carbonic anhydrase. Its preparation and properties. J. Physiol. 80, 113-142. doi: 10.1113/jphysiol.1933.sp003077

Parasuraman, S., Raveendran, R., and Kesavan, R. (2010). Blood sample collection in small laboratory animals. J. Pharmacol. Pharmacother. 1, 87-93. doi: 10.4103/0976-500X.72350

Parkkila, S., Parkkila, A. K., Juvonen, T., Waheed, A., Sly, W. S., Saarnio, J., et al. (1996). Membrane-bound carbonic anhydrase IV is expressed in the luminal plasma membrane of the human gallbladder epithelium. Hepatolology 24, 1104-1108. doi: 10.1002/hep.510240521

Pasini, E. M., Kirkegaard, M., Mortensen, P., Lutz, H. U., Thomas, A. W., and Mann, M. (2006). In-depth analysis of the membrane and cytosolic proteome of red blood cells. Blood 108, 791-801. doi: 10.1182/blood-2005-11-007799

Pazdzior, G., Langner, M., Chmura, A., Bogusławska, D., Heger, E., Chorzalska, A., et al. (2003). The kinetics of haemolysis of spherocytic erythrocytes. Cell. Mol. Biol. Lett. 8, 639-648.

Philo, J. S., Adams, M. L., and Schuster, T. M. (1981). Association-dependent absorption spectra of oxyhemoglobin A and its subunits. J. Biol. Chem. 256, 7917-7924.
Pocker, Y., and Bjorkquist, D. W. (1977). Comparative studies of bovine carbonic anhydrase in $\mathrm{H}_{2} \mathrm{O}$ and $\mathrm{D}_{2} \mathrm{O}$. Stopped-flow studies of the kinetics of interconversion of $\mathrm{CO}_{2}$ and $\mathrm{HCO}_{3}$. Biochemistry 16, 5698-5707. doi: 10.1021/bi00645a008

Prahl, S. (1998). Tabulated Molar Extinction Coefficient for Hemoglobin in Water. Available online at: http://omlc.org/spectra/hemoglobin/summary.html (Accessed July 17, 2016).

Purkerson, J. M., and Schwartz, G. J. (2007). The role of carbonic anhydrases in renal physiology. Kidney Int. 71, 103-115. doi: 10.1038/sj.ki.5002020

Sanyal, G., Swenson, E. R., Pessah, N. I., and Maren, T. H. (1982). The carbon dioxide hydration activity of skeletal muscle carbonic anhydrase. Inhibition by sulfonamides and anions. Mol. Pharmacol. 22, 211-220.

Scheibe, R. J., Gros, G., Parkkila, S., Waheed, A., Grubb, J. H., Shah, G. N., et al. (2006). Expression of membrane-bound carbonic anhydrases IV, IX, and XIV in the mouse heart. J. Histochem. Cytochem. 54, 1379-1391. doi: 10.1369/jhc.6A7003.2006

Sendroy, J. Jr. and Rodkey, F. L. (1961). Apparent dissociation constant of phenol red as determined by spectrophotometry and by visual colorimetry. Clin. Chem. 7, 646-654.

Shingles, R., and Moroney, J. V. (1997). Measurement of carbonic anhydrase activity using a sensitive fluorometric assay. Anal. Biochem. 252, 190-197. doi: 10.1006/abio.1997.2305

Sly, W. S., and Hu, P. Y. (1995). Human carbonic anhydrases and carbonic anhydrase deficiencies. Annu. Rev. Biochem. 64, 375-401. doi: 10.1146/annurev.bi.64.070195.002111

Stadie, W. C., and O'Brien, H. (1933). The catalysis of the hydration of carbon dioxide and dehydration of carbonic acid by an enzyme isolated from red blood cells. J. Biol. Chem. 103, 521-552.

Stemler, A. (1993). An assay for carbonic anhydrase activity and reactions that produce radiolabeled gases or small uncharged molecules. Anal. Biochem. 210, 328-331. doi: 10.1006/abio.1993.1203

Supuran, C. T. (2016). Structure and function of carbonic anhydrases. Biochem. J. 473, 2023-2032. doi: 10.1042/BCJ20160115

Tashian, R. E., and Carter, N. D. (1976). "Biochemical genetics of carbonic anhydrase," in Advances in Human Genetics, eds H. Harris and K. Hirschhorn (Springer US), 1-56.

Wang, X., Conway, W., Burns, R., McCann, N., and Maeder, M. (2010). Comprehensive study of the hydration and dehydration reactions of carbon dioxide in aqueous solution. J. Phys. Chem. A 114, 1734-1740. doi: 10.1021/jp909019u

Wilbur, K. M., and Anderson, N. G. (1948). Electrometric and colorimetric determination of carbonic anhydrase. J. Biol. Chem. 176, 147-154.

Wistrand, J., Lindahl, S., and Wåhlstrand, T. (1975). Human renal carbonic anhydrase. Purification and properties. Eur. J. Biochem. 57, 189-195. doi: $10.1111 /$ j.1432-1033.1975.tb02290.x

Wistrand, P. J., Carter, N. D., Conroy, C. W., and Mahieu, I. (1999). Carbonic anhydrase IV activity is localized on the exterior surface of human erythrocytes. Acta Physiol. Scand. 165, 211-218. doi: 10.1046/j.1365-201x.1999.00478.x

Zhao, J., Hogan, E. M., Bevensee, M. O., and Boron, W. F. (1995). Out-ofequilibrium $\mathrm{CO}_{2} / \mathrm{HCO}_{3}^{-}$solutions and their use in characterizing a new $\mathrm{K} / \mathrm{HCO}_{3}$ cotransporter. Nature 374, 636-639. doi: 10.1038/374636a0

Conflict of Interest Statement: The authors declare that the research was conducted in the absence of any commercial or financial relationships that could be construed as a potential conflict of interest.

Copyright $\odot 2017$ Zhao, Geyer and Boron. This is an open-access article distributed under the terms of the Creative Commons Attribution License (CC BY). The use, distribution or reproduction in other forums is permitted, provided the original author(s) or licensor are credited and that the original publication in this journal is cited, in accordance with accepted academic practice. No use, distribution or reproduction is permitted which does not comply with these terms. 